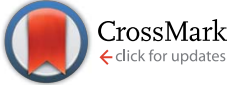

Cite this: Chem. Sci., 2015, 6, 5601

\title{
In vivo demonstration of an active tumor pretargeting approach with peptide nucleic acid bioconjugates as complementary system $\dagger$
}

\author{
Anna Leonidova, $\$^{\mathrm{a}}$ Christian Foerster, $\$ \S^{\mathrm{b}}$ Kristof Zarschler, ${ }^{\mathrm{b}}$ Maik Schubert, ${ }^{\mathrm{b}}$

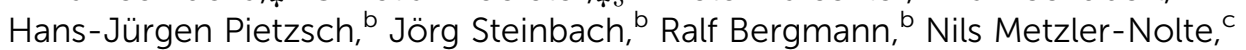 \\ Holger Stephan ${ }^{\star b}$ and Gilles Gasser ${ }^{\star a}$
}

\begin{abstract}
A novel, promising strategy for cancer diagnosis and therapy is the use of a pretargeting approach. For this purpose, the non-natural DNA/RNA analogues Peptide Nucleic Acids (PNAs) are ideal candidates as in vivo recognition units due to their high metabolic stability and lack of unspecific accumulation. In the pretargeting approach, an unlabeled, highly specific antibody-PNA conjugate has sufficient time to target a tumor before administration of a small fast-clearing radiolabeled complementary PNA that hybridizes with the antibody-PNA conjugate at the tumor site. Herein, we report the first successful application of this multistep process using a PNA-modified epidermal growth factor receptor (EGFR) specific antibody (cetuximab) and a complementary ${ }^{99 \mathrm{~m}} \mathrm{Tc}$-labeled PNA. In vivo studies on tumor bearing mice demonstrated a rapid and efficient in vivo hybridization of the radiolabeled PNA with the antibodyPNA conjugate. Decisively, a high specific tumor accumulation was observed with a tumor-to-muscle ratio of $>8$, resulting in a clear visualization of the tumor by single photon emission computed tomography (SPECT).
\end{abstract}

Received 16th March 2015

Accepted 16th June 2015

DOI: $10.1039 / \mathrm{c} 5 \mathrm{sc00951k}$

www.rsc.org/chemicalscience

\section{Introduction}

The excellent target specificity of monoclonal antibodies (mAbs) renders this class of biomacromolecules a beneficial platform to detect and treat tumor malignancies. In nuclear medicine, such tumor antigen-specific vehicles labeled with radionuclides

${ }^{a}$ Department of Chemistry, University of Zurich, Winterthurerstrasse 190, CH-8057 Zurich, Switzerland. E-mail: gilles.gasser@chem.uzh.ch; Web: http://www. gassergroup.com; Tel: +41446354630

${ }^{b}$ Helmholtz-Zentrum Dresden - Rossendorf, Institute of Radiopharmaceutical Cancer Research, Bautzner Landstraße 400, D-01328 Dresden, Germany. E-mail: $h$. stephan@hzdr.de; Web: http://www.hzdr.de/NanoscalicSystems; Tel: +49 351 2603091

${ }^{c}$ Lehrstuhl für Anorganische Chemie I - Bioanorganische Chemie, Fakultät für Chemie und Biochemie, Ruhr-Universität Bochum, Universitätsstrasse 150, D-44801 Bochum, Germany

$\dagger$ Electronic supplementary information (ESI) available: Characterization of the PNAs used this study (Fig. S1-14), radio HPLC of

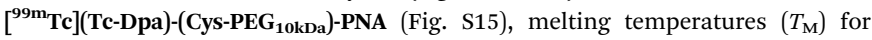
three complementary 17-mer PNA systems (Table S1), melting curves of

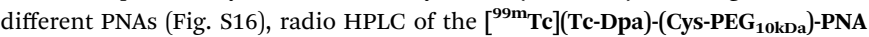
(original), in rat arterial blood plasma (Fig. S17), biodistribution of radiolabeled PNAs in Wistar rats (\%ID mean \pm SD) (Table S2), biodistribution of radiolabeled PNAs in Wistar rats (SUV mean \pm SD) (Table S3), SPECT/CT comparison of the biodistribution of [ ${ }^{99 m}$ Tc] (Tc-Dpa)-(Cys-PEG 10kDa -PNA in rat and mouse (Fig. S18). See DOI: 10.1039/c5sc00951k

\$ These authors have contributed equally to the work.

$\S$ Current address: Department of Oncology, University of Alberta, 11560 University Avenue, Edmonton, Alberta, T6G1Z2, Canada. would be applicable for non-invasive imaging of diseases and more importantly, for in vivo delivery of therapeutically relevant radioactivity doses to tumor sites. Unfortunately, the concept of utilizing radionuclide-carrying tumor-specific mAbs is afflicted with several drawbacks, ${ }^{1-3}$ mainly arising from the high molecular weight of mAbs $(\sim 150 \mathrm{kDa})$. Due to size-related limitations in passing biological barriers, ${ }^{4}$ such as extravasation and the inability of glomerular filtration, mAbs exhibit a slow but gradual accumulation in tumor sites and long blood retention times of up to several days, respectively. ${ }^{5}$ The slow blood clearance rate of mAbs forces extensive waiting times before acquiring a diagnostic image with reasonable signal-tobackground ratio as well as to label with appropriate isotopes. ${ }^{6,7}$ Detrimental radiation exposure for almost all tissues in the organism, especially during therapeutic applications, will be the result of their prolonged blood pool retention time. ${ }^{8}$ Despite innumerable research activities and efforts conducted so far, only two drugs, namely Bexxar ${ }^{\circledR}$ and Zevalin ${ }^{\mathrm{TM}}$, representing radiolabeled mAbs for treatment of Non-Hodgkin's lymphoma are currently approved by the FDA. ${ }^{9-11}$

An attractive strategy to circumvent these limitations is the use of a pretargeting approach that involves an artificial in vivo recognition system composed of a nonradioactive antibody conjugate and a small radiolabeled "effector" molecule. As schematically represented in Scheme 1 , in this multistep process, an unlabeled, highly tumor-specific antibody conjugate is first administrated into a patient. Upon injection, sufficient 
time is allowed for the antibody conjugate to reach the tumor and to be eliminated from the non targeted tissues. This is then followed by the administration of a small fast-clearing radiolabeled "effector" molecule that binds to the antibody conjugate at the tumor site. ${ }^{\mathbf{1 2 , 1 3}}$ This approach allows for the rational use of long-circulating high-affinity mAbs for both non-invasive cancer radioimmunodetection and radioimmunotherapy. ${ }^{\mathbf{1 4 , 1 5}}$

Several recognition systems have been investigated and to some extend clinically tested for different pretargeting approaches. Most prominent among them are streptavidin/ biotin, ${ }^{16-19}$ bispecific antibody/hapten ${ }^{20-27}$ and synthetic complementary oligonucleotides/oligonucleotides such as morpholino and peptide nucleic acid derivatives. ${ }^{28-34}$ For more detailed information and secondary references, we highly recommend the review article of Goldenberg et al. ${ }^{35}$ Beside the "classical" recognition by supramolecular motifs, bio-orthogonal and ultra-fast click reactions have also been developed as complementary system in vivo. ${ }^{36-39}$

Among the range of synthetic oligonucleotides investigated for pretargeting, phosphorodiamidate morpholino oligomers (MORFs) and Peptide Nucleic Acids (PNAs, Scheme 1) have emerged as promising candidates. Both derivatives are noncharged mimics of the naturally occurring ribonucleic acids DNA and RNA. They exhibit a suitable degree of water solubility, are almost inert towards degradation in vivo, ${ }^{\mathbf{4 0 , 4 1}}$ and insensitive towards chemical modifications even under harsh conditions. The superior intrinsic properties of PNAs over DNA/RNA have made them extremely interesting candidates for applications in (nuclear) medicine or biology. Radiolabeled PNA oligomers were indeed utilized as probes for molecular imaging of target specific mRNA sequences. ${ }^{\mathbf{4 2}-48}$ However, the relatively low cellular uptake of PNAs has represented a serious drawback, which has undoubtedly delayed their use as antisense or antigen agents, although several techniques are now available to overcome this problem (e.g. use of cell-penetrating peptides, etc.). Nonetheless, the limited cellular uptake of PNAs creates a very interesting bio-orthogonal system. Indeed, administration of a radiolabeled PNA strand into a living organism rarely results into unspecific binding. ${ }^{34,48}$ In other words, the PNA strand is usually excreted in its intact form from the kidney/ liver. This characteristic, in addition to the excellent physicochemical properties discussed above, have made PNAs a promising tool in the tumor pretargeting approach.

Pioneering work in this field of research was performed by Hnatowich and co-workers, who demonstrated a first proof-ofconcept in 1997..$^{32-34,49}$ In those studies, surrogates such as PNAloaded polymeric ${ }^{32,34}$ and agarose-based avidin beads ${ }^{49}$ transplanted into mouse thighs were used. To the best of our knowledge, there is only a single report describing the utilization of PNA-streptavidin bioconjugates for (non-specific) tumor localization in a mouse model by passive diffusion. ${ }^{33}$ These PNA-protein conjugates were found to accumulate unspecifically in most tissues of the animals. Consequently, upon administration of the radiolabeled complementary PNA, radioactivity levels were significantly higher compared to control animals. However, tumor antigens have not been specifically targeted by anti-tumor antibody-PNA conjugates yet. Thus, a critical evaluation of a tumor pretargeting concept in vivo is still lacking.

In this work, we aim to demonstrate the suitability of PNA-based bioconjugates as versatile complementary system for the specific transportation and accumulation of radionuclides in tumors. More specifically, in this article, we first describe the preparation and characterization of several PNA bioconjugates that contained different building blocks such as a 2,2'-dipicolylamine (Dpa) to chelate the radioactive ${ }^{99 \mathrm{~m}} \mathrm{Tc}$ as well as polyethylene glycol (PEG) units to tune the biodistribution of the PNA oligomers. In addition, radiolabeling of the Dpa-containing bioconjugates with $\left[{ }^{99 m} \mathbf{T c}\right] \mathbf{T c}\left(\mathbf{H}_{2} \mathbf{O}\right)_{3}(\mathbf{C O})_{3}{ }^{+}$ as well as detailed radiopharmaceutical evaluation including biodistribution and metabolic profiling is presented.

Of note, to critically assess the PNA-based pretargeting system used in this work, the well-studied, FDA-approved therapeutic mAb cetuximab (C225; Erbitux®, ImClone LLC) was selected, since it is commercially available and shows chemical robustness as well as a high affinity to a clinically relevant tumor biomarker. ${ }^{50-54}$ The molecular target of cetuximab, namely the epidermal growth factor receptor (EGFR), ${ }^{55,56}$ is involved in regulating cell growth, differentiation and survival of cells. ${ }^{57,58}$ In a variety of human malignancies, EGFR is constitutively activated as a result of receptor overexpression, mutation or deregulation ${ }^{59-61}$ and has therefore been investigated as a major target for the treatment of uncontrolled tumor growth. ${ }^{62-64}$ All in all, this article demonstrates, for the first time, the successful tumor pretargeting approach using radiolabeled PNAs in combination with PNA-antibody bioconjugates in murine xenografts (human squamous carcinoma cell line A431). This report highlights the immense potential of this approach for both cancer radioimmunodetection as well as radioimmunotherapy.

\section{Results and discussion}

\section{Synthesis and characterization of PNA bioconjugates}

All PNA oligomers and bioconjugates were synthesized manually on TentaGel S Fmoc-Lys(Boc)-RAM resin using commercially available Fmoc/Bhoc-protected PNA monomers and standard protocols previously reported by our groups. ${ }^{65}$ For sufficient stability of PNA-PNA hybrids, complementary PNA oligomers consisting of 17 bases were designed. Table 1 summarizes the PNA sequences used in this work. In order to radiolabel PNA with $\left[{ }^{99 \mathrm{~m}} \mathrm{Tc}\right] \mathrm{Tc}\left(\mathrm{H}_{2} \mathrm{O}\right)_{3}(\mathrm{CO})_{3}{ }^{+}, 2,2^{\prime}$-dipicolylamine (Dpa) was site-specifically introduced by copper-mediated 1,3dipolar cycloaddition ("Click" Chemistry) as previously reported by our groups. ${ }^{66}$ In order to improve the pharmacokinetics and bioavailability of compounds and drug carriers, we envisaged PEGylating the PNA bioconjugates as described in the literature for different biomolecules. ${ }^{67-73}$ However, in the different studies having investigated the use of PEG-containing PNAs oligomers, the full impact of PEGylation on PNA's pharmacokinetics and biodistribution was not assessed..$^{65,74-82}$

Of note, some of us recently demonstrated that PEGylation of 17-mer L-configured DNA-oligonucleotides - another promising complementary system $\quad-\quad$ significantly altered 

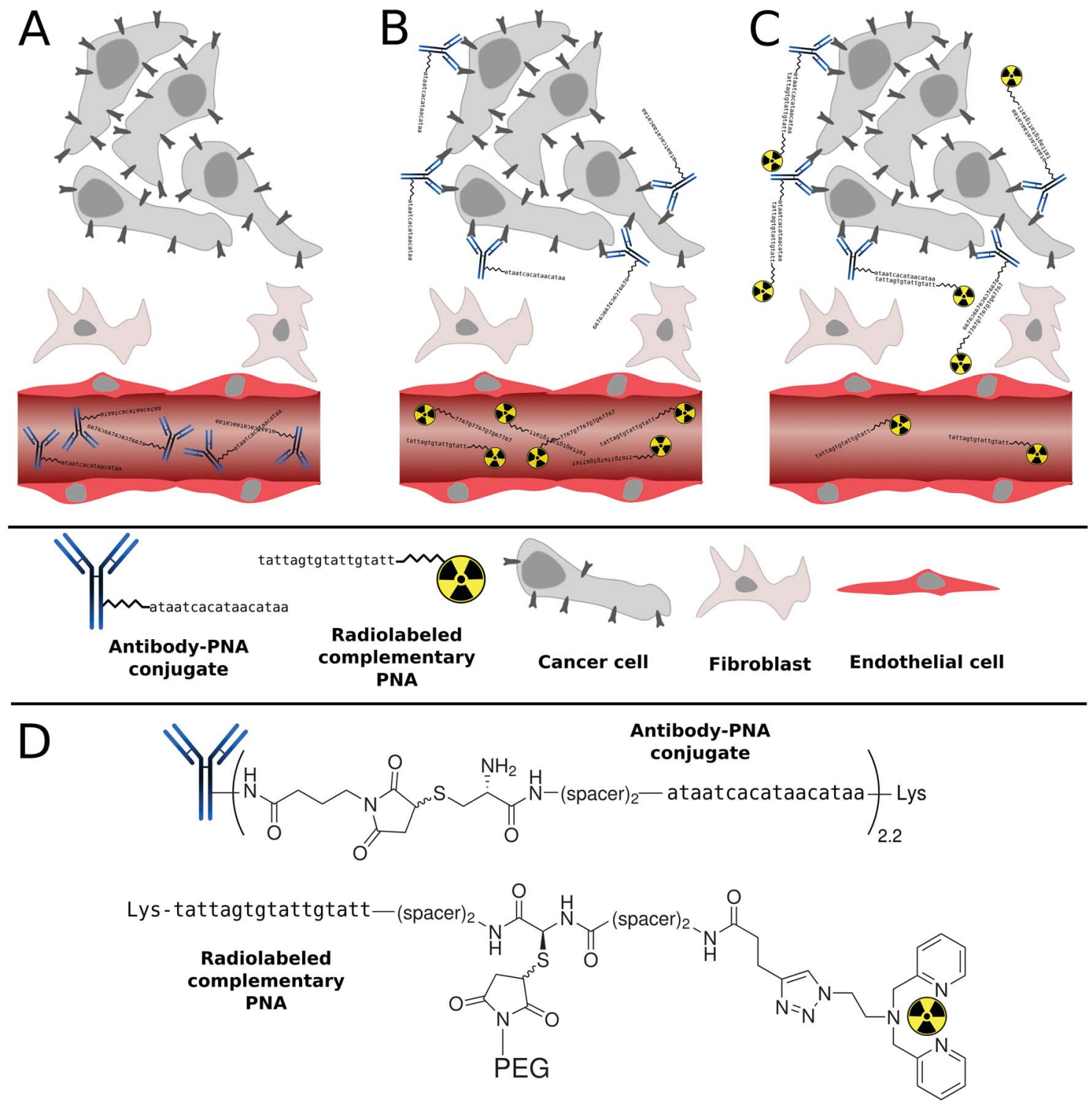

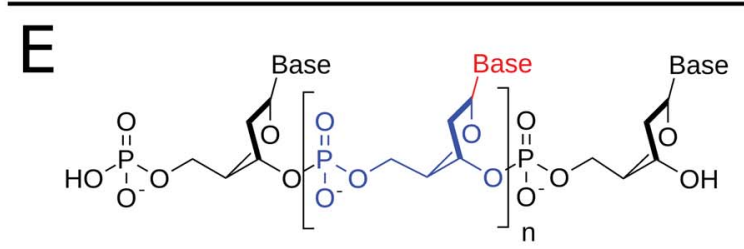

DNA

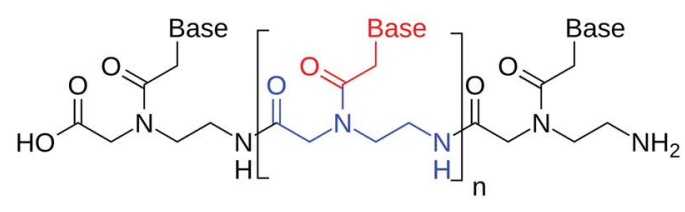

PNA

Scheme 1 General principle of tumor pretargeting using Peptide Nucleic Acids (PNA). Firstly, unlabeled, highly specific antibody-PNA conjugates are administered intravenously into the patient (A). After accumulation of the antibody conjugates at the tumor site and clearance from non-target tissues, small fast-clearing radiolabeled complementary PNAs are injected (B), that hybridize with antibody-PNA conjugates (C). The radioactivity symbols inserted into the $2,2^{\prime}$ - dipicolylamine (Dpa) chelator illustrate either ${ }^{99 \mathrm{~m}} \mathrm{Tc}(\mathrm{CO})_{3}$ or ${ }^{186} \mathrm{Re}(\mathrm{CO})_{3}$, which are used for diagnosis or therapy, respectively (D). While DNA has a deoxyribose sugar backbone, the PNA's backbone is composed of repeating $N$-(2-aminoethyl)glycine units linked by amide bonds. Their various purine and pyrimidine bases are linked to the backbone by a methylene bridge and a carbonyl group (E).

radiopharmacokinetics. Indeed, a non-specific accumulations in kidneys was markedly reduced by $90 \%$, while the blood circulation half-life was strongly increased by factor of $4 .^{83}$ More specifically, in this work, two different PNA bioconjugates, namely Dpa-PNA and Dpa-Cys-PNA (Entries 1 and 2 in Table 1), were first synthesized as radionuclide carriers. Maleimido-PEG derivatives (2 and $10 \mathrm{kDa}$ ) were then inserted via Michael-type addition into the cysteine-containing PNA Dpa-Cys-PNA to give Dpa-(Cys-PEG $\left.{ }_{2 \mathrm{kDa}}\right)-\mathrm{PNA}$ and Dpa-(Cys-PEG 10kDa$)-\mathrm{PNA}$, respectively (Entries 4 and 5 in Table 1). For this purpose, pretreatment 
Table 1 Summary of the PNA oligomers used in this study

\begin{tabular}{|c|c|c|}
\hline Entry & Abbreviation & Sequence $^{a}$ \\
\hline 1 & Dpa-PNA & H-Dpa-spacer-spacer-ttatgttatgtgattat-Lys- $\mathrm{NH}_{2}$ \\
\hline 2 & Dpa-Cys-PNA & H-Dpa-spacer-spacer-Cys-spacer-spacer-ttatgttatgtgattat-Lys- $\mathrm{NH}_{2}$ \\
\hline 4 & Dpa-(Cys-PEG 2kDa $\left._{2}\right)$ PNA & H-Dpa-spacer-spacer-(Cys-PEG ${ }_{2 \mathrm{kDa}}$ )-spacer-spacer-ttatgttatgtgattat-Lys- $\mathrm{NH}_{2}$ \\
\hline 5 & Dpa-(Cys-PEG $\left.{ }_{10 k D a}\right)-P N A$ & H-Dpa-spacer-spacer-(Cys- $\mathrm{PEG}_{10 \mathrm{kDa}}$ )-spacer-spacer-ttatgttatgtgattat-Lys- $\mathrm{NH}_{2}$ \\
\hline 6 & $(\mathrm{NOTA})_{3}$-C225-Cys-c-PNA & $(\mathrm{NOTA})_{3}$-C225-mal-Cys-spacer-spacer-ataatcacataacataa-Lys- $\mathrm{NH}_{2}$ \\
\hline
\end{tabular}

of Dpa-Cys-PNA with the strong reducing agent tris(2-carboxyethyl)phosphine (TCEP) was found to be necessary to improve the yields of conjugation reaction by preventing PNA-PNA disulfide dimer formation. ${ }^{74,80}$ Prior to the addition of maleimido-PEG derivatives, excessive TCEP was removed by size exclusion chromatography to avoid reduction of $\mathrm{C}-\mathrm{C}$ double bond of maleimide entity leading to sulfhydryl-unreactive succinimide derivatives. In addition, a cysteine-containing PNA oligomer, Cys-c-PNA (Entry 3 in Table 1), which is complementary to the other PNA sequences of this study, was prepared. The identity of all PNA analogues Dpa-PNA, Dpa-Cys-PNA, Cys-c-PNA, Dpa(Cys-PEG 2kDa $_{\text {-PNA, and Dpa-(Cys-PEG }}$ 10kDa)-PNA was confirmed by ESI-MS and MALDI-TOF MS. The high purity of the bioconjugates was verified by LC-MS (Fig. S2, S5, S8, S10 and S12 $\dagger$ ). Apart from the $[\mathrm{M}+n \mathrm{H}]^{n+}$ peaks, additional $[\mathrm{M}+\mathrm{Cu}+n \mathrm{H}]^{n+},[\mathrm{M}-$ picolyl $+\mathrm{Cu}+n \mathrm{H}]^{n+}$ were also observed in both ESI and MALDITOF spectra for Dpa-containing products. This effect is due to the traces of copper ions still present after the introduction of Dpa to PNA sequence by "Click" Chemistry. Due to the polydispersity of PEG polymers combined with the multiple charged conjugates, ESI-MS generated spectra with multitudinous $\mathrm{m} / \mathrm{z}$ peaks disabling conclusive results. The presence of Dpa-(Cys-PEG $\left.\mathbf{P L D a}_{\mathbf{2}}\right)$ -

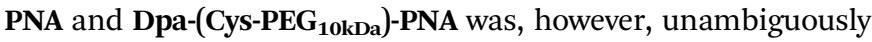
confirmed by MALDI-TOF, where only single and double positive charged species were observed (Fig. S11, S13†).

\section{Hybridization properties}

In order to assess self-complementary interactions between the PNA strands, we performed UV-based melting curves for each single stranded PNA oligomers, namely Cys-c-PNA, Dpa-PNA,

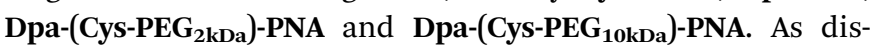
played in Fig. $\mathrm{S} 16+$, no homo-hybridization was observed. In the case of hetero-hybridization, our data listed in Table $\mathrm{S} 1 \dagger$ show that, even at room temperature, Cys-c-PNA forms perfect hybrids with all other PNA derivatives (complete match). The determined melting temperatures were almost independent of the degree of PEGylation.

\section{Bioconjugation between Cys-c-PNA and cetuximab}

Cetuximab (C225; Erbitux®, ImClone LLC), a chimeric humanmurine IgG1 monoclonal antibody, binds specifically to the extracellular domain of the epidermal growth factor receptor (EGFR) on both normal and tumor cells, and competitively inhibits the binding of epidermal growth factor (EGF) as well as other ligands. EGFR is often overexpressed in human malignancies and is associated with poor clinical prognosis. ${ }^{\mathbf{8 4 , 8 5}}$ Cetuximab binding to EGFR blocks phosphorylation. This blockage results in inhibition of downstream cellular processes such as induction of apoptosis and cell growth. Due to its promising antitumor activity, cetuximab has been approved for the treatment of colorectal and head and neck squamous cell carcinoma as well as with external radiotherapy for the treatment of head and neck squamous cell carcinoma. ${ }^{86}$ Of note, we have recently shown that cetuximab labeled with the therapeutic $\beta$-emitter ${ }^{90} \mathrm{Y}$ could improve permanent local tumor control after external radiotherapy. ${ }^{52}$ Since this well-studied anti-EGFR antibody possesses a high affinity to its molecular target, shows chemical robustness and is commercially available, we selected it as model for radiopharmaceutical evaluation of our PNA-based pretargeting system.

Prior to attachment of Cys-c-PNA to cetuximab, the antiEGFR antibody was modified with 1,4,7-triazacyclononane1,4,7-triacetic acid (NOTA), ${ }^{87}$ a suitable $\left[{ }^{64} \mathrm{Cu}\right] \mathrm{Cu}^{2+}$ chelator for PET-monitoring of aspired PNA-cetuximab bioconjugate. ${ }^{\mathbf{8 8 - 9 1}}$ This allows us to quantify such important parameters as blood circulation half-life and tumor accumulation of PNA-cetuximab and therefore to optimize the administration regime of PNAcetuximab conjugate and radiolabeled PNA. NOTA was successfully conjugated to cetuximab resulting in an average of three NOTA molecules per antibody to give (NOTA) ${ }_{3}$-C225.

Subsequent introduction of a maleimido group to (NOTA) ${ }_{3}$ C225 was successfully performed by reaction of (NOTA) $)_{3}$-C225 with 4-maleimido-butyric acid $N$-succinimidyl ester (GMBS) to obtain (NOTA) ${ }_{3}$-C225-mal.

Finally, Cys-c-PNA was linked to (NOTA) ${ }_{3}$-C225-mal under mild reaction conditions to give the bioconjugate (NOTA) ( $^{-}$ C225-Cys-c-PNA (Entry 6 in Table 1). The average number of conjugated Cys-c-PNA to (NOTA) ( $_{3}$-C225-mal was quantified by determination of the absorbance ratio $260 \mathrm{~nm} / 280 \mathrm{~nm}$ in the UV spectrum. ${ }^{92-94}$ Based on this method, $2.2 \pm 0.7$ Cys-c-PNA moieties per antibody were found. MALDI-TOF MS analysis confirmed this result since the determined number of 2.4 bound PNA oligomers per antibody is in the same range as calculated by UV method (see Fig. S14†).

\section{Radiochemistry}

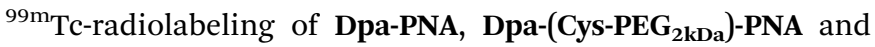

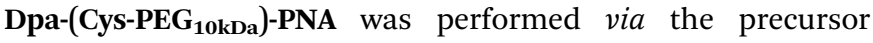


Table 2 Partition coefficients $\log D_{\circ / \mathrm{w}}$ of radiolabeled PNA conjugates at different $\mathrm{pH}$ values ${ }^{a}$

\begin{tabular}{|c|c|c|c|c|}
\hline $\mathrm{pH}$ value & $\begin{array}{l}\text { 12-mer }\left[{ }^{99 m} \mathbf{T c}\right](\mathbf{T c}-D p a)-P N A \\
\text { from ref. } 48\end{array}$ & $\begin{array}{l}\text { 17-mer }\left[{ }^{99 m} \mathrm{Tc}\right](\mathrm{Tc}-\mathrm{Dpa})- \\
\text { PNA }\end{array}$ & $\begin{array}{l}\text { 17-mer }\left[{ }^{99 m} \text { Tc]}(T c-D p a)-\right. \\
(\text { Cys-PEG } \\
\text { 2kDa)-PNA }\end{array}$ & $\begin{array}{l}\text { 17-mer }\left[{ }^{99 m_{T}} \text { Tc]}(\text { Tc-Dpa)- }\right. \\
\text { (Cys-PEG }{ }_{10 k D a} \text { )-PNA }\end{array}$ \\
\hline 7.2 & -0.86 & $-(2.35 \pm 0.04)$ & $-(2.28 \pm 0.07)$ & $-(2.40 \pm 0.02)$ \\
\hline 7.6 & -0.84 & $-(2.35 \pm 0.07)$ & $-(2.42 \pm 0.06)$ & $-(2.35 \pm 0.02)$ \\
\hline
\end{tabular}

${ }^{a}$ Shown are the averages of three independent experiments with the standard deviation in parentheses.

$\left[{ }^{99 \mathrm{~m}} \mathrm{Tc}\left(\mathrm{H}_{2} \mathrm{O}\right)_{3}(\mathrm{CO})_{3}\right]^{+}$generated by the IsoLink ${ }^{\circledR}$ kit "Carbonyl Labeling Agent". ${ }^{95}$ Highly concentrated $\left[{ }^{99 \mathrm{~m}} \mathrm{Tc}\left(\mathrm{H}_{2} \mathrm{O}\right)_{3}(\mathrm{CO})_{3}\right]^{+}$ precursor with radiochemical yields (rcy) of $>95 \%$ was obtained by concentrating the solution at $100{ }^{\circ} \mathrm{C}$ for $30 \mathrm{~min}$. Up to $580 \mathrm{MBq}$ of ${ }^{99 \mathrm{~m}} \mathrm{Tc}$ precursor was added to $10 \mathrm{nmol}$ of each of the Dpa-bearing PNA conjugates to give the corresponding radiolabeled PNA conjugates with rcy $>95 \%$ and high effective specific activities of up to $58 \mathrm{GBq} \mu \mathrm{mol}^{-1}(n=19)$. Detailed studies to improve radiolabeling conditions have shown a strong dependency of rcy on the $\mathrm{pH}$ of the radiolabeling mixture. Radiolabeling at $\mathrm{pH}<7$ resulted in incomplete complexation of $\left[{ }^{99 m} \mathrm{Tc}(\mathrm{CO})_{3}\right]^{+}$with rcy of $<85 \%$, while the rcy went to up to $>95 \%$ at optimized conditions $\left(70{ }^{\circ} \mathrm{C}, 40 \mathrm{~min}\right.$, $10 \mathrm{nmol}$ of PNA conjugate) when $\mathrm{pH}$ in the range from 7 to 8 was applied.

After purification of ${ }^{99 \mathrm{~m}}$ Tc-labeled PNA derivatives by HPLC, partition experiments were performed in 1-octanol/buffer systems to assess the lipophilicity/hydrophobicity of the radiolabeled PNAs. Distribution ratio $\log D_{\mathrm{o} / \mathrm{w}}$ was determined at three different $\mathrm{pH}$ values (Table 2). Surprisingly, the $\log D$ values were almost independent on the degree of PEGylation within the tested $\mathrm{pH}$ range (7.2-7.6). Compared with previously published results based on a 12-mer PNA conjugate, ${ }^{48}$ it appears that the hydrophilicity is increased more by the lengthening of the PNA chain from 12-mer to 17-mer, rather than by the PEGylation.

In order to examine if the modification of cetuximab with Cys-c-PNA resulted in loss of affinity to the EGFR, the antibody derivatives (NOTA) ${ }_{3}$-C225 and (NOTA) $)_{3}$-C225-Cys-c-PNA were radiolabeled with $\left[{ }^{64} \mathrm{Cu}\right] \mathrm{CuCl}_{2}$. Of note, the $\mathrm{pH}$ of the $\left[{ }^{64} \mathrm{Cu}\right]$ $\mathrm{CuCl}_{2}$ labeling solution had to be adjusted to around 6 prior addition to the solutions containing the cetuximab conjugates to avoid antibody denaturation. In addition, due to the sensitivity of the antibody, mild reaction conditions $\left(30^{\circ} \mathrm{C}\right.$ without shaking) were used. (NOTA) $)_{3}$-C225 and (NOTA) $)_{3}$-C225-Cys-cPNA were labeled with effective specific activities of up to $16.7 \mathrm{GBq} \mu \mathrm{mol}^{-1}$ and radiochemical yields $>99 \%$.

\section{Affinity of $\left[{ }^{64} \mathrm{Cu}\right] \mathrm{Cu}$-(NOTA) ${ }_{3}$-C225-Cys-c-PNA and $\left[{ }^{64} \mathrm{Cu}\right] \mathrm{Cu}-$ (NOTA) ${ }_{3}$-C225 to the EGFR}

In order to evaluate the influence of PNA-conjugation on the antibody's binding specificity and affinity to human EGFR, the dissociation characteristics of $\left[{ }^{64} \mathrm{Cu}\right] \mathrm{Cu}$-(NOTA) $)_{3}$-C225-Cys-cPNA and $\left[{ }^{64} \mathbf{C u}\right] \mathrm{Cu}$-(NOTA) $)_{3}$-C225 were determined comparatively using two dimensional cell cultures of epidermoid carcinoma (A431) and squamous carcinoma (FaDu) cells. These tumor cell lines present different expression levels of the receptor on their cell surface. ${ }^{96}$

Fig. 1 shows the saturation binding curves of radiolabeled cetuximab conjugates for both cell lines. For $\left[{ }^{64} \mathrm{Cu}\right] \mathrm{Cu}-(\mathrm{NOTA})_{3^{-}}$ C225-Cys-c-PNA and $\left[{ }^{64} \mathrm{Cu}\right] \mathrm{Cu}-(\mathrm{NOTA})_{3}{ }_{3}$-C225, Scatchard analysis was applied to determine dissociation constants (Table 3). A $K_{\mathrm{d}}$ of $5.4 \pm 0.9 \mathrm{nM}$ and $B_{\max }$ of $13.3 \mathrm{pmol}$ per mg protein for A431 and a $K_{\mathrm{d}}$ of $1.1 \pm 0.2 \mathrm{nM}$ and $B_{\max }$ of 1.9 pmol per mg protein for FaDu cells were obtained for $\left[{ }^{64} \mathbf{C u}\right] \mathrm{Cu}-(\mathrm{NOTA})_{3}$ C225-Cys-c-PNA. $\quad\left[{ }^{64} \mathrm{Cu}\right] \mathrm{Cu}-(\mathrm{NOTA})_{3}$-C225 showed slightly different dissociation constants with a $K_{\mathrm{d}}$ of $7.7 \pm 0.8 \mathrm{nM}$ and $B_{\max }$ of 15.9 pmol per $\mathrm{mg}$ protein for A431 and a $K_{\mathrm{d}}$ of $2.0 \pm$ $0.3 \mathrm{nM}$ and $B_{\max }$ of 2.9 pmol per mg protein for FaDu cells. Modification of the monoclonal antibody with PNAs does not affect its binding behavior to EGFR expressing tumor cells. This is of particular importance since the immunoreactivity as well
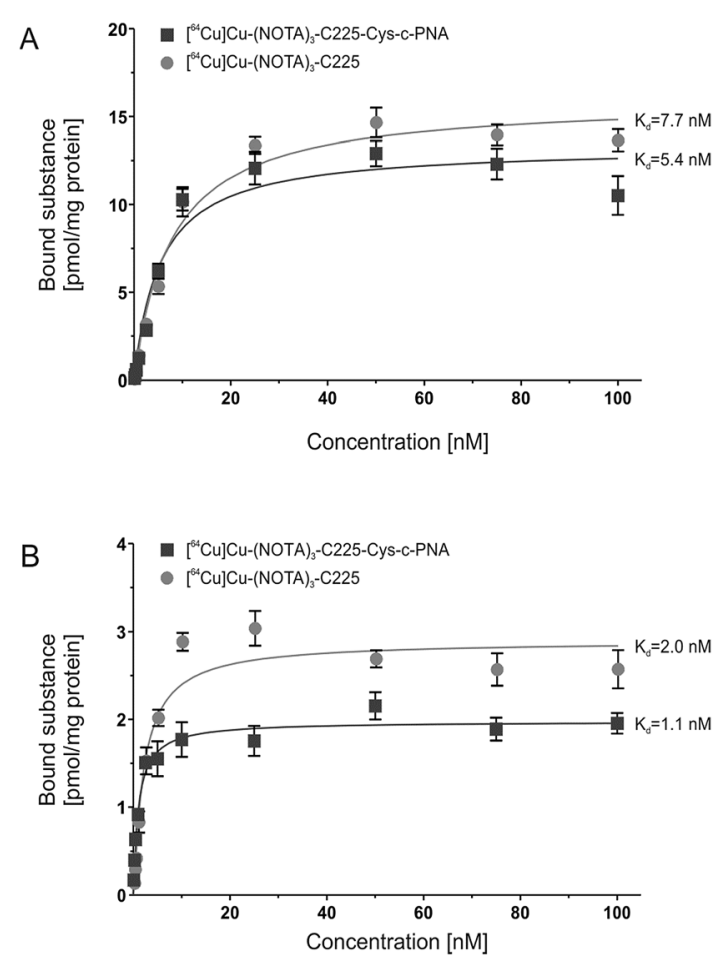

Fig. 1 In vitro binding studies of radiolabeled cetuximab conjugates. Saturation curves of $\left[{ }^{64} \mathrm{Cu}\right] \mathrm{Cu}-(\mathrm{NOTA})_{3}-\mathrm{C} 225-\mathrm{Cys}-\mathrm{c}-\mathrm{PNA}$ and $\left[{ }^{64} \mathrm{Cu}\right]$ $\mathrm{Cu}$-(NOTA) $)_{3}-\mathrm{C} 225$ upon incubation with human EGFR-positive tumor cell lines A431 (A) and FaDu (B). 
Table 3 In vitro binding characteristics of radiolabeled cetuximab conjugates to human EGFR-positive tumor cells

\begin{tabular}{llll}
\hline & & $\begin{array}{l}\left.{ }^{64} \mathrm{Cu}\right] \mathrm{Cu}-(\mathrm{NOTA})_{3} \mathbf{C}^{-\mathrm{C225}-} \\
\text { Cys-c-PNA }\end{array}$ & $\begin{array}{l}\left.{ }^{64} \mathrm{Cu}\right] \mathrm{Cu}-(\mathrm{NOTA})_{3^{-}} \\
\mathbf{C 2 2 5}\end{array}$ \\
\hline \multirow{2}{*}{$\mathrm{A} 431$} & $K_{\mathrm{d}}$ & $5.4 \pm 0.9 \mathrm{nM}$ & $7.7 \pm 0.8 \mathrm{nM}$ \\
& $B_{\max }$ & $13.3 \pm 0.6 \mathrm{pmol} \mathrm{mg}^{-1}$ & $15.9 \pm 0.4 \mathrm{pmol} \mathrm{mg}^{-1}$ \\
FaDu & $K_{\mathrm{d}}$ & $1.1 \pm 0.2 \mathrm{nM}$ & $2.0 \pm 0.3 \mathrm{nM}$ \\
& $B_{\max }$ & $1.9 \pm 0.1 \mathrm{pmol} \mathrm{mg}^{-1}$ & $2.9 \pm 0.1 \mathrm{pmol} \mathrm{mg}^{-1}$
\end{tabular}

as the high affinity of cetuximab to EGFR has to be conserved after chemical conjugation. ${ }^{56}$

The variation in the affinity of the antibody conjugates between A431 and FaDu cells can be explained by the different cellular context. Such an effect has been previously reported for EGF ${ }^{97}$ Björkelund and co-workers indeed observed an important influence of the investigated cell lines on the binding characteristics and on the multiple ligand-receptor interactions. The authors explained these phenomena by the occurrence of varying ratios of EGFR homodimers and heterodimers composed of EGFR and the human epidermal growth factor receptor 2 (HER2) due to different expression levels of these receptors. The different ratios of EGFR and HER2 may also account for the herein described variation in the affinity of the cetuximab conjugates between A431 and FaDu cells. The former cell line overexpresses EGFR with $1-3 \times 10^{6}$ receptors per cell ${ }^{98}$ and has a lower HER2 expression, ${ }^{96,99,100}$ whereas the latter cell line possesses a large HER2 population and presents less EGFR on the cell surface $\left(7 \times 10^{5}\right.$ receptors per cell $){ }^{96,99,101}$

\section{Biodistribution studies}

The data previously presented by Hnatowich and coworkers $^{32-34,49}$ and by our laboratories ${ }^{48}$ demonstrated favorable properties of radiolabeled PNAs towards in vivo tumor pretargeting applications. These include very fast distribution, low non-specific accumulation in non-targeted tissue as well as renal elimination as preferred elimination pathway from organism. However, these experiments also showed that specific accumulation of radiolabeled PNA derivatives in pretargeted tumor tissue might not be sufficiently high for therapeutic approaches. ${ }^{33,34,49}$ The reason behind it is certainly the rapid elimination of the radiolabeled PNA from blood. The major aim of attaching large PEG moieties onto our 17-mer PNA oligomers was therefore to increase blood retention and subsequently enhance blood availability. This should result into increased hybridization incidences in pretargeted tumor tissue.

As an initial step of this evaluation process, we determined the impact of the degree of PEGylation on the radiopharmacological behavior by conducting biodistribution studies and dynamic SPECT scans in healthy male Wistar rats. To ensure comparability and compatibility with further animal studies as well as published results, the data presented are the means \pm standard deviation of standard uptake values (SUV), defined as the tracer concentration at a certain time point normalized to injected dose per unit body weight. Detailed biodistribution data presented as SUV and \%ID are summarized in Tables S2 and S3.† At 5 min post injection (Table 4), the ${ }^{99} \mathrm{~m}$ Tc-labeled 17-mer PNA conjugates clearly showed an elevated level of activity concentration in the blood pool with increasing degree of PEGylation. Compared to the non-PEGylated 17-mer Dpa-PNA, the attachment of PEG led to about 10\% and $45 \%$ higher activity concentration in the blood pool for 2 kDa PEG and 10 kDa PEG, respectively.

In agreement with the concept of tumor pretargeting, ${ }^{102}$ all radiolabeled PNA conjugates were distributed by the blood stream very rapidly and were almost completely eliminated from the blood pool $60 \mathrm{~min}$ after administration. This

Table 4 Biodistribution data for ${ }^{99 \mathrm{~m}}$ Tc-labeled PNA derivatives performed in healthy male Wistar rats at 5 min and 60 min after single intravenous injection. Data are presented as SUV

\begin{tabular}{|c|c|c|c|c|c|c|}
\hline & \multicolumn{2}{|c|}{ 17-mer $\left[{ }^{99 m} \mathbf{T c}\right](T c-D p a)-P N A$} & \multicolumn{2}{|c|}{$\begin{array}{l}\text { 17-mer }\left[{ }^{99 m_{1}} \text { Tc] }\right](T c-D p a)-(C y s- \\
\left.\text { PEG }_{2 \text { kDa }}\right) \text {-PNA }\end{array}$} & \multicolumn{2}{|c|}{$\begin{array}{l}\text { 17-mer }\left[{ }^{99 m_{\text {Tc}}} \text { Te (Tc-Dpa)-(Cys- }\right. \\
\text { PEG }_{10 k D a} \text {-PNA }\end{array}$} \\
\hline & $\begin{array}{l}5 \text { min p.i. } \\
(n=12)\end{array}$ & $\begin{array}{l}60 \text { min p.i. } \\
(n=11)\end{array}$ & $\begin{array}{l}5 \text { min p.i. } \\
(n=8)\end{array}$ & $\begin{array}{l}60 \text { min p.i. } \\
(n=8)\end{array}$ & $\begin{array}{l}5 \text { min p.i. } \\
(n=8)\end{array}$ & $\begin{array}{l}60 \text { min p.i. } \\
(n=8)\end{array}$ \\
\hline Blood & $1.36 \pm 0.21$ & $0.24 \pm 0.10$ & $1.51 \pm 0.13$ & $0.24 \pm 0.06$ & $2.01 \pm 0.38$ & $0.34 \pm 0.11$ \\
\hline Kidneys & $11.7 \pm 1.60$ & $13.1 \pm 1.99$ & $12.0 \pm 1.42$ & $9.29 \pm 1.10$ & $11.3 \pm 1.86$ & $9.75 \pm 2.64$ \\
\hline Adrenals & $0.56 \pm 0.12$ & $0.14 \pm 0.04$ & $0.80 \pm 0.25$ & $0.32 \pm 0.21$ & $0.82 \pm 0.15$ & $0.25 \pm 0.08$ \\
\hline Liver & $0.91 \pm 0.23$ & $0.85 \pm 0.26$ & $1.12 \pm 0.42$ & $0.98 \pm 0.42$ & $1.15 \pm 0.21$ & $0.73 \pm 0.30$ \\
\hline Spleen & $0.59 \pm 0.31$ & $0.22 \pm 0.04$ & $0.92 \pm 0.29$ & $0.71 \pm 0.34$ & $0.60 \pm 0.13$ & $0.54 \pm 0.46$ \\
\hline Pancreas & $0.51 \pm 0.30$ & $0.14 \pm 0.16$ & $0.35 \pm 0.04$ & $0.26 \pm 0.25$ & $0.51 \pm 0.06$ & $0.61 \pm 1.24$ \\
\hline Thymus & $0.46 \pm 0.09$ & $0.10 \pm 0.02$ & $0.46 \pm 0.08$ & $0.10 \pm 0.01$ & $0.45 \pm 0.06$ & $0.12 \pm 0.04$ \\
\hline Muscles & $0.38 \pm 0.16$ & $0.05 \pm 0.01$ & $0.35 \pm 0.03$ & $0.09 \pm 0.04$ & $0.30 \pm 0.08$ & $0.13 \pm 0.09$ \\
\hline Lung & $1.06 \pm 0.18$ & $0.22 \pm 0.06$ & $2.30 \pm 0.69$ & $2.16 \pm 1.36$ & $1.41 \pm 0.24$ & $0.42 \pm 0.16$ \\
\hline Heart & $0.58 \pm 0.07$ & $0.10 \pm 0.04$ & $0.64 \pm 0.06$ & $0.13 \pm 0.04$ & $0.81 \pm 0.21$ & $0.17 \pm 0.06$ \\
\hline Femur & $0.56 \pm 0.03$ & $0.16 \pm 0.02$ & $0.45 \pm 0.01$ & $0.14 \pm 0.03$ & $0.51 \pm 0.07$ & $0.16 \pm 0.04$ \\
\hline Testicles & $0.25 \pm 0.13$ & $0.09 \pm 0.02$ & $0.34 \pm 0.14$ & $0.13 \pm 0.03$ & $0.34 \pm 0.08$ & $0.16 \pm 0.03$ \\
\hline Hadrian glands & $0.57 \pm 0.08$ & $0.12 \pm 0.03$ & $0.58 \pm 0.18$ & $0.18 \pm 0.15$ & $0.59 \pm 0.09$ & $0.17 \pm 0.04$ \\
\hline Brain & $0.04 \pm 0.01$ & $0.01 \pm 0.00$ & $0.04 \pm 0.00$ & $0.02 \pm 0.02$ & $0.07 \pm 0.02$ & $0.01 \pm 0.01$ \\
\hline Hair \& Skin & $0.79 \pm 0.07$ & $0.24 \pm 0.11$ & $0.93 \pm 0.08$ & $0.24 \pm 0.03$ & $0.86 \pm 0.19$ & $0.28 \pm 0.07$ \\
\hline
\end{tabular}


Table 5 Comparison of ${ }^{99} \mathrm{~m}$ Tc activity concentration of radiolabeled 17-mer PNA conjugates of current studies with previously published 12 -mer $\mathrm{PNA}^{48}$ in healthy male Wistar rats at $5 \mathrm{~min}$ and $60 \mathrm{~min}$ after single intravenous injection. Data are presented as SUV

\begin{tabular}{|c|c|c|c|c|}
\hline & $\begin{array}{l}\text { 12-mer [ }{ }^{99 m} \text { Tc]-(Tc-Dpa)-PNA } \\
\text { from ref. } 48\end{array}$ & 17-mer [ ${ }^{99 m_{1}}$ Tc]-(Tc-Dpa)-PNA & $\begin{array}{l}\text { 17-mer }\left[{ }^{99 m} \text { Tc }\right](\text { Tc-Dpa)-(Cys- } \\
\text { PEG }_{2 \text { kDa }} \text {-PNA }\end{array}$ & $\begin{array}{l}\text { 17-mer }\left[{ }^{99 m_{1}} \text { Tc }\right](T c-D p a)-(C y s- \\
\text { PEG }_{\text {10kDa }} \text {-PNA }\end{array}$ \\
\hline $\begin{array}{l}\text { Blood } 5 \text { min p.i. } \\
\text { (60 min p.i.) }\end{array}$ & $1.21 \pm 0.05(0.26 \pm 0.10)$ & $1.36 \pm 0.21(0.24 \pm 0.10)$ & $1.51 \pm 0.13(0.24 \pm 0.06)$ & $2.01 \pm 0.38(0.34 \pm 0.11)$ \\
\hline $\begin{array}{l}\text { Kidneys } 5 \text { min p.i. } \\
\text { (60 min p.i.) }\end{array}$ & $7.12 \pm 0.43(5.45 \pm 0.45)$ & $11.7 \pm 1.60(13.11 \pm 1.99)$ & $12.0 \pm 1.42(9.29 \pm 1.10)$ & $11.3 \pm 1.86(9.75 \pm 2.64)$ \\
\hline $\begin{array}{l}\text { Liver } 5 \text { min p.i. } \\
(60 \text { min p.i.) }\end{array}$ & $0.99 \pm 0.03(0.67 \pm 0.10)$ & $0.91 \pm 0.23(0.85 \pm 0.26)$ & $1.12 \pm 0.42(0.98 \pm 0.42)$ & $1.15 \pm 0.21(0.73 \pm 0.30)$ \\
\hline
\end{tabular}

minimizes unpredictable whole-body radiation exposure. As expected for compounds with molecular weights significantly lower than $30 \mathrm{kDa}$ and of highly hydrophilic nature (see $\log D_{\mathrm{o} / \mathrm{w}}$ values from Table 2), the activity was almost exclusively eliminated via the renal pathway.

Compared with previously published results on a 12-mer PNA conjugate $\left[{ }^{99 m} \mathbf{T c}\right]\left(\right.$ Tc-Dpa-PNA) ${ }^{48}$ the expansion to a 17-mer conjugate enhanced blood availability 5 min p.i. by about $12 \%$ (Table 5).

In combination with the attachment of a PEG moiety, we were able to further elevate blood availability to $25 \%$ and $66 \%$ for $2 \mathrm{kDa}$ PEG and $10 \mathrm{kDa}$ PEG, respectively. The increase in the length of the PNA sequence from 12-mer to 17-mer also led to higher kidney uptake from $(7.12 \pm 0.43)$ SUV to $(11.71 \pm$ 1.60) SUV and $(5.45 \pm 0.45)$ SUV to $(13.11 \pm 1.99)$ SUV $5 \mathrm{~min}$ and $60 \mathrm{~min}$ post injection, respectively. Similar relationship between the length of oligonucleotide sequence and kidney retention has been reported for morpholino-type oligonucleotides $^{92}$ and has also been observed, in a much greater extent, for L-configured DNA-oligonucleotides in our laboratories. ${ }^{83}$

Based on compiled data (see Fig. 2), among the 17-mer PNA conjugates used in this study, $\left.{ }^{{ }^{99 m}} \mathbf{T c}\right]($ Tc-Dpa)-(Cys-PEG 10kDa PNA exhibits the highest activity concentration in the blood
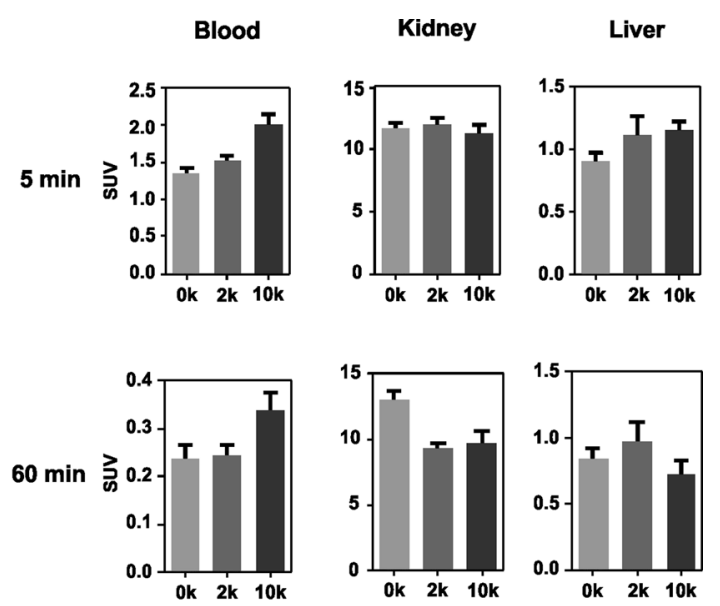

Fig. 2 Comparison of activity concentration (SUV) in the blood, kidneys and liver of rats after single intravenous injection following sacrifice at 5 and $60 \mathrm{~min}$ p.i.

pool and the lowest activity concentration in liver and kidney tissue (60 min p.i.) combined with a trend of wash-out from those organs. This promising 17-mer PNA conjugate was therefore further evaluated by dynamic SPECT scans.

SPECT image 5 min post injection (Fig. 3) substantiated an almost homogeneous blood distribution with enhanced activity concentration in heart, left and right carotids, both kidneys with hotspots at the renal pelvis, and bladder (urine). As demonstrated with the SPECT images at 60 min post injection, the majority of activity has been eliminated from blood pool via kidneys into the bladder. The calculated activity-under-curve (AUC) projection clearly shows removal of activity by renal pathway.

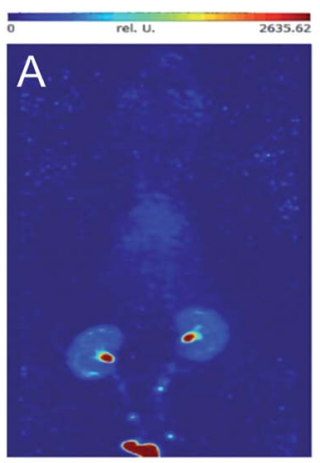

5 min p.i.

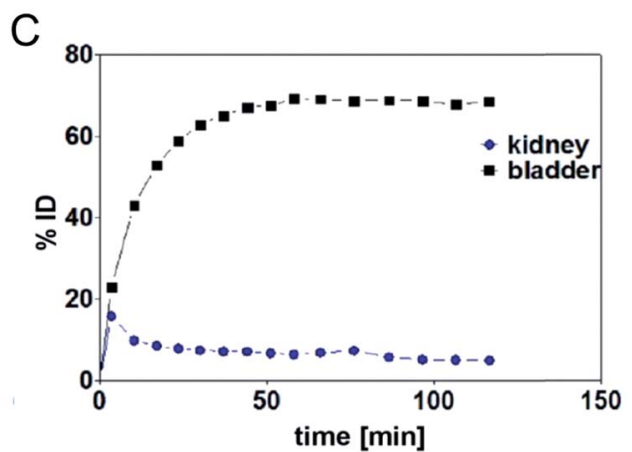

Fig. 3 Maximum intensity projections generated from dynamic SPECT ( $A$ and $B$ ) and calculated activity-under-curve for bladder and kidney tissue of $\left[{ }^{99 m} \mathrm{Tc}\right](\mathrm{Tc}-\mathrm{Dpa})-\left(\mathrm{Cys}-\mathrm{PEG}_{10 \mathrm{kDa}}\right)$-PNA (C) after single intravenous administration in single healthy male Wistar rat (SPECT/CT images and tumor mouse are presented in Fig. S18†). 
Radio-HPLC analysis of [ ${ }^{99 m}$ Tc](Tc-Dpa)-(Cys-PEG 10kDa $)-P N A$ samples from rat arterial blood, kidney extracts and urine showed no metabolic degradation over a time period of $120 \mathrm{~min}$ post injection (Fig. S17†).

\section{Evaluation of the pretargeting approach}

These promising radiopharmaceutical results strongly encouraged us to investigate the tumor pretargeting approach using

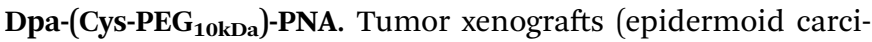
noma) were obtained after subcutaneous injection of A431 cells into the right thigh of female NMRI nu/nu mice. Imaging and biodistribution studies were performed when the tumor were in the range of 8 to $13 \mathrm{~mm}$.

The control experiment in this xenograft model without pretreatment of (NOTA) $)_{3}$-C225-Cys-c-PNA before injection of

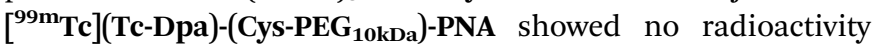
localization in tumor site (Fig. 4A). The remaining radioactivity after $1 \mathrm{~h}$ p.i. is mainly located in the kidneys as expected on the basis of biodistribution experiments with rats described above.

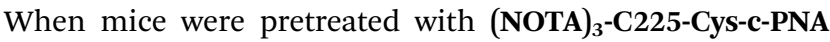
$24 \mathrm{~h}$ prior to administration of [ ${ }^{\mathbf{9 9}} \mathbf{T c}$ Tc(Tc-Dpa)-(Cys-PEG $\left.\mathbf{1 0 k D a}_{\mathbf{1 0}}\right)$ PNA, SPECT images clearly demonstrated an accumulation of radioactivity at tumor site referring to efficient and rapid in vivo hybridization at pretargeted tumor tissue. The tumor is clearly visible after $60 \mathrm{~min}$ (Fig. 4B) and the radioactivity can be detected for at least 1 day (Fig. 4C). The enhanced radioactivity level in the kidneys, liver and blood compared to the control experiment is due to the circulating antibody conjugate. The activity wash-out from blood and tissues is faster relative to the tumor. Altogether, the tumor pretargeting using PNA allows for fast tumor localization and can be considered for improved in vivo targeting.

For more detailed evaluation of our pretargeting approach, we also conducted biodistribution studies in eight murine xenografts, applying the same experimental conditions as described for SPECT imaging (single intravenous injection of (NOTA) ${ }_{3}$-C225-Cys-c-PNA $24 \mathrm{~h}$ prior to administration of

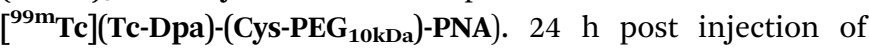
[ $\left.{ }^{99 m_{\text {Tc}}}\right]($ Tc-Dpa)-(Cys-PEG 10kDa $)$-PNA, an enhanced radioactivity concentration of SUV $0.63 \pm 0.27$ was determined in tumor tissue (Fig. 5). Compared with non-targeted muscle tissue, a high contrast of tumor-to-muscle ratio of $8.29 \pm 1.28$ was achieved. The elevated levels of activity concentration in blood, liver, heart, and lung may be explained by incomplete blood elimination of (NOTA) $)_{3}$-C225-Cys-c-PNA. It is very likely that circulating (NOTA) $)_{3}$-C225-Cys-c-PNA formed hybrids with

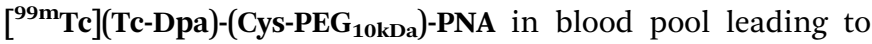
enhanced retention time of activity in blood and aforementioned organs. This is in agreements with findings for PNAstreptavidin conjugates circulating in the blood to be able to efficiently bound radiolabeled complementary PNA. ${ }^{33}$

Although a distinct accumulation of activity in the tumor site was observed $60 \mathrm{~min}$ after the administration of radiolabeled complementary PNAs to pretargeted mice, the resulting tumorto-blood ratios might not be ideal. We determined that the waiting period of $24 \mathrm{~h}$ between both administrations represented the optimal balance in terms of rate of blood clearance and rate of internalization of PNA-cetuximab conjugates. On one hand, extended intervals such as $72 \mathrm{~h}$ would enhance blood clearance of the antibody-PNA conjugates as well as decrease activity concentration in blood, liver, heart, and lung. On the other hand, PNA-cetuximab conjugates bound to EGF-receptors are undergoing internalization via receptormediated endocytosis, which gradually diminishes the amount of hybridization events with radiolabeled complementary PNAs. For this reason, we believe that extended waiting will not significantly enhance tumor-to-background ratios.
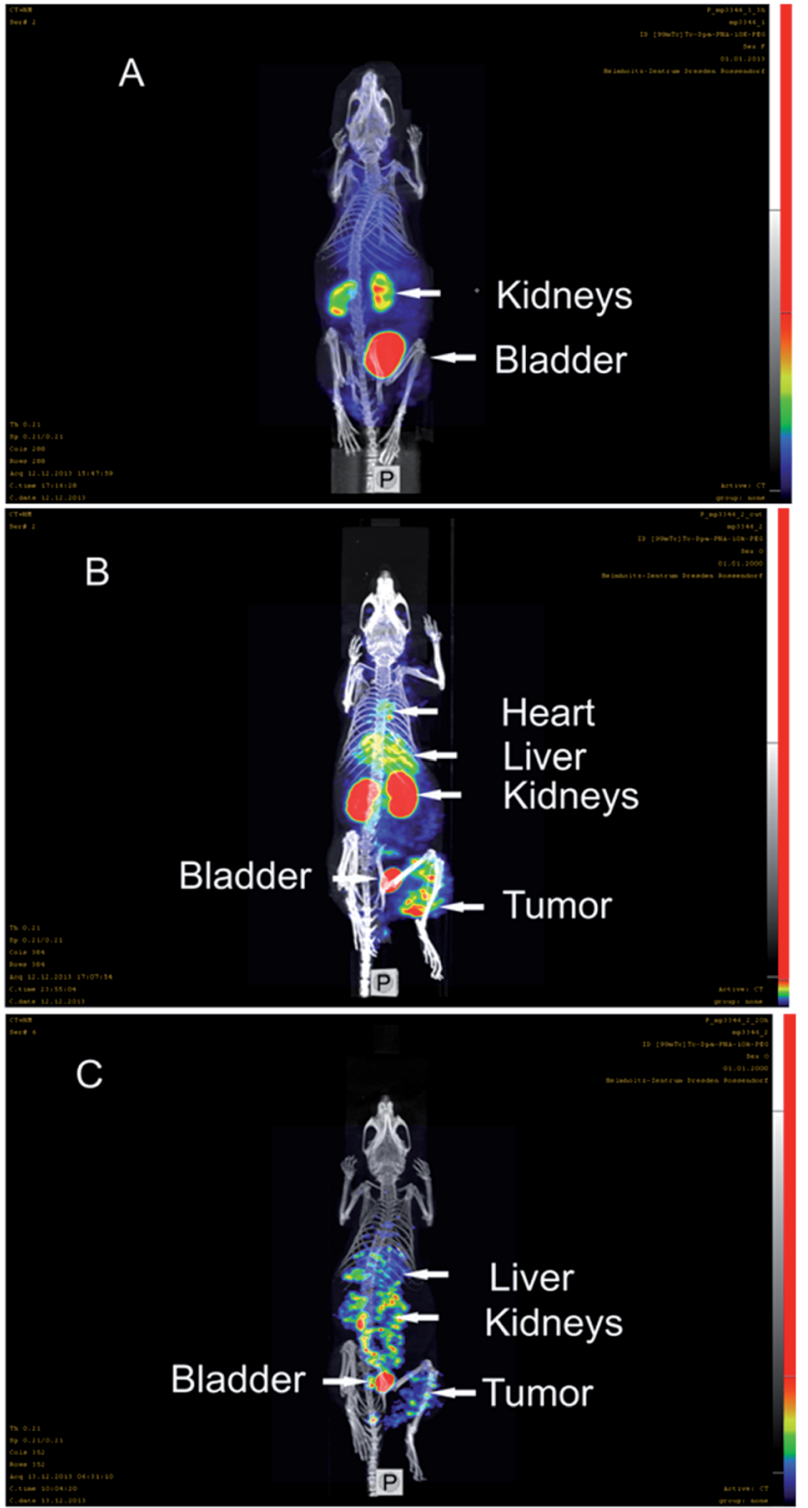

Fig. 4 SPECT/CT maximum intensity projection images of [ $\left.{ }^{99 m} \mathrm{Tc}\right](\mathrm{Tc}-$ Dpa)-(Cys-PEG $10 \mathrm{kDa}$ )-PNA in murine A431 tumor xenograft (NMRI nu/ nu mice; tumor located at right thigh). (A) $1 \mathrm{~h}$ post injection of $\left[{ }^{99 m} \mathrm{Tc}\right](\mathrm{Tc}-\mathrm{Dpa})-\left(\mathrm{Cys}-\mathrm{PEG}_{10 \mathrm{kDa}}\right)-\mathrm{PNA}$ without preinjection of (NOTA) 3-C225-Cys-c-PNA. (B) $1 \mathrm{~h}$ post injection of radiotracer; (NOTA) 3 C225-Cys-c-PNA was administered $24 \mathrm{~h}$ before injection of radiotracer. (C) $20 \mathrm{~h}$ post injection of radiotracer; (NOTA) 3 -C225-Cys-cPNA was administered $24 \mathrm{~h}$ before injection of radiotracer. 


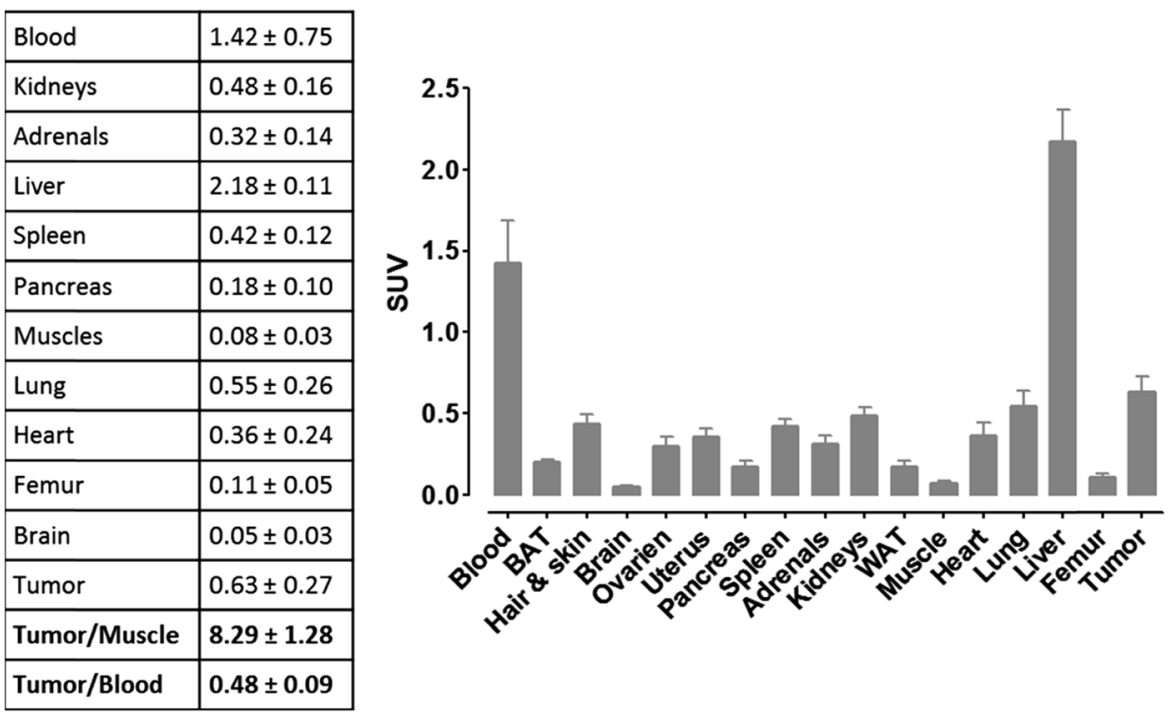

Fig. 5 Biodistribution of [ $\left.{ }^{99 m} \mathrm{Tc}\right](\mathrm{Tc}-\mathrm{Dpa})-\left(\mathrm{Cys}-\mathrm{PEG}_{10 \mathrm{kDa}}\right)-\mathrm{PNA}$ (24 h post injection of radiotracer) in murine xenograft (NMRI nu/nu mice; A431 tumor cells transplanted into right thigh) $24 \mathrm{~h}$ after single administration of (NOTA) ${ }_{3}$-C225-Cys-c-PNA. Values in the table are averages in SUV including standard deviation (8 mice).

\section{Conclusions}

The search for novel radiotheragnostic modalities for the detection and treatment of cancer is currently attracting a lot of attention worldwide. Among the different options investigated, the use of a pretargeting approach with the non-natural DNA/ RNA analogues Peptide Nucleic Acids (PNAs) as recognition units is extremely attractive. ${ }^{33}$ By temporally separated administration of the antibody-PNA conjugate and its radiolabeled complementary PNA counterpart, the important limitations of conventional directly radiolabeled antibodies are overcome. Among these limitations, slow blood clearance has been identified as a major hurdle for diagnostic tumor discrimination, requiring extensive waiting times, which can last up to a week after administration before image acquisition. Furthermore, $\mathrm{mAb}$ accumulation in non-target tissues results in radiation damage to non-tumor cells and subsequently in severe toxicity. ${ }^{\mathbf{8}}$ The herein exemplified pretargeting approach using PNAs facilitates the rational use of mAb conjugates for diagnostic and therapeutic purposes since it allows for sufficient time for the antibody-PNA conjugate to find the target tissue and for the rapid clearance of the radioactive PNA construct from circulation and normal tissues.

By eliminating the hitherto existing limitations of PNAs such as insufficient water solubility as well as unfavorable biodistribution, ${ }^{41}$ we successfully optimized this complementary system for future pretargeting approaches. Nonetheless, the herein obtained results for our PNA-based approach cannot be juxtaposed with reported studies applying phosphorodiamidate morpholino oligomers (MORFs) due to major divergences with respect to animal models, tumor entities as well as tumor cellrelated molecular targets and corresponding antibodies. Neglecting these facts, similar tumor uptake and non-target ratios were achieved..$^{28,31}$ All in all, as demonstrated in this article, PNAs are a favorable alternative to MORFs for this field of research, especially when considering their relatively facile synthesis.

More specifically, in this article, we initially described the first detailed radiopharmaceutical evaluation of PNA bioconjugates for tumor pretargeting. We could then demonstrate that the PEGylation of PNA oligomers resulted into optimized pharmacokinetic properties. Compared with their non-PEGylated analogue, PEGylated PNAs showed lower kidney and liver accumulation, better renal excretion and a more beneficial residence time in blood. We also present a versatile conjugation protocol to modify the EGFR specific therapeutic antibody cetuximab. Coupling of a cysteine-functionalized PNA oligomer to the mAb equipped with maleimido functional groups was achieved at ambient temperature. As expected, under these conditions, the modification of cetuximab with the PNA conjugate did not affect its binding properties towards EGFRpositive tumor cells showing hence that this modified antibody could be used in our study. Very importantly, in vivo studies in tumor bearing mice demonstrated the high potential of the described pretargeting approach. Rapid and efficient in vivo hybridization of a fast-clearing radiolabeled complementary PNA with a cetuximab-PNA conjugate led to high specific tumor accumulation. The studies performed have shown that the 17mer PNAs investigated are promising candidates for further preclinical studies. All in all, this study opens up new avenues not only in the field of radioimaging but also in the field of cancer radioimmunotherapy. We are currently analyzing if such an approach could be used to treat cancer by using therapeutic radionuclides such as ${ }^{90} \mathrm{Y},{ }^{177} \mathrm{Lu},{ }^{186} \mathrm{Re}$ or ${ }^{188} \mathrm{Re}$.

\section{Experimental section}

\section{Material and methods}

Chemicals and solvents were of reagent grade or better and purchased from commercial suppliers and were used without 
further purification unless otherwise specified. Alpha-methoxyomega-ethyl-maleimide poly(ethylene glycol) (MeO-PEG-mal; MeO-PEG ${ }_{2 \mathrm{kDa}}$-maleimide with PDI = 1.03; MeO-PEG $_{\mathbf{1 0 k D a}}$-maleimide with PDI $=1.08$ ) and $N$-alpha-(9-fluorenylmethyloxycarbonyl)- $S$-trityl-L-cysteine (Fmoc-L-Cys(Trt)-OH) were purchased from Iris Biotech. PNA monomers were supplied by Link technologies. TentaGel S RAM Lys(Boc) Fmoc resin was purchased from Rapp Polymere. 2,2'-dipicolylamine (Dpa- $\mathbf{N}_{3}$ ) was prepared following a previously reported procedure. ${ }^{48}$ All other chemicals were of reagent-grade and sourced from SigmaAldrich.

ESI-MS spectra were recorded on a Bruker Esquire 6000. The matrix-assisted laser desorption/ionization time of flight mass spectrometry (MALDI-TOF) mass spectra were measured on a Bruker Daltonics Autoflex. The experiments were performed in reflector (RP) or linear (LP) mode with positive polarity using $\alpha$ cyano-4-hydroxy-cinnamic acid on a Prespotted AnchorChip (PAC HCCA) or sinapinic acid (SA) as the matrix. LC-MS spectra were measured on an Acquity ${ }^{\mathrm{TM}}$ from Waters system equipped with a PDA detector and an auto sampler using an Agilent Zorbax 300SB-C18 analytical column (3.5 $\mu \mathrm{m}$ particle size, $300 \AA$ pore size, $150 \times 4.6 \mathrm{~mm}$ ). This LC was coupled to an Esquire HCT from Bruker (Bremen, Germany) for the MS measurements. The LC run (flow rate: $0.3 \mathrm{~mL} \mathrm{~min}^{-1}$ ) was performed with a linear gradient of A (distilled water containing $0.1 \% \mathrm{v} / \mathrm{v}$ formic acid) and B (acetonitrile (Sigma-Aldrich HPLC-grade), containing $0.1 \% \mathrm{v} / \mathrm{v}$ formic acid); $t=0 \mathrm{~min}, 5 \% \mathrm{~B} ; t=3 \mathrm{~min}, 5 \%$ $\mathrm{B} ; t=17 \mathrm{~min}, 100 \% \mathrm{~B} ; t=20 \mathrm{~min}, 100 \% \mathrm{~B} ; t=25 \mathrm{~min}, 5 \% \mathrm{~B}$. HPLC purification was performed on a Varian ProStar system equipped with a UV/Vis spectrometer and an Agilent Zorbax 300SB-C18 prep column (5 $\mu \mathrm{m}$ particle size, $300 \AA$ pore size,

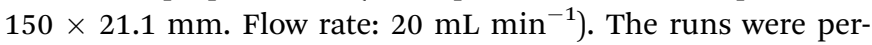
formed with a linear gradient of A (distilled water containing $0.1 \% \mathrm{v} / \mathrm{v}$ TFA) and B (acetonitrile (Sigma-Aldrich HPLC-grade), containing $0.1 \% \mathrm{v} / \mathrm{v}$ TFA). Preparative run: $t=0 \mathrm{~min}, 5 \% \mathrm{~B} ; t=$ $17 \mathrm{~min}, 42 \% \mathrm{~B} ; t=25 \mathrm{~min}, 100 \% \mathrm{~B} ; t=30 \mathrm{~min}, 100 \% \mathrm{~B} ; t=$ $32 \mathrm{~min}, 5 \% \mathrm{~B}$ (for Dpa-PNA, Dpa-Cys-PNA and Cys-c-PNA). Preparative runs: $t=0 \mathrm{~min}, 10 \% \mathrm{~B} ; t=24 \mathrm{~min}, 60 \% \mathrm{~B} ; t=$ $25 \mathrm{~min}, 100 \% \mathrm{~B} ; t=30 \mathrm{~min}, 100 \% \mathrm{~B} ; t=32 \mathrm{~min}, 10 \% \mathrm{~B}$ (for Dpa-(Cys-PEG $\boldsymbol{x}_{\boldsymbol{x}}$ )-PNA). The size exclusion purification was performed on an AKTAprime Plus system using HiTrap Desalting $5 \times 5 \mathrm{~mL}$ GE Healthcare $(10 \mathrm{mM} \mathrm{HCl}$ in distilled water, flow rate $\left.3 \mathrm{~mL} \mathrm{~min}^{-1}\right)$. Radio-HPLC of the ${ }^{99 \mathrm{~m}} \mathrm{Tc}$ labeled Dpa-PNA derivatives were performed on a Perkin-Elmer system with quaternary pump (series 200 LC pump) equipped with a radiodetector (RAMONA from raytest), a UV/Vis-detector (LC 290 from Perkin-Elmer) and an Eurosphere 100 column (5 $\mu \mathrm{m}$ particle size, $200 \mathrm{~mm} \times 4.5 \mathrm{~mm}$, flow rate: $\left.1 \mathrm{~mL} \min ^{-1}\right)$. The runs were performed with a linear gradient of $\mathrm{A}$ (distilled water containing $0.1 \% \mathrm{v} / \mathrm{v}$ TFA) and B (acetonitrile Fisher HPLC-grade, containing $0.1 \% \mathrm{v} / \mathrm{v}$ TFA): $t=0 \mathrm{~min}, 0 \% \mathrm{~B} ; t=20 \mathrm{~min}, 100 \% \mathrm{~B}$. Supernatants from samples of arterial blood plasma were analyzed on a Hewlett Packard system (series 1100) equipped with a radio-detector (RAMONA from raytest) and a Zorbax C18 $300 \mathrm{SB}$ column ( $4 \mu \mathrm{m}$ particle size, $9.4 \times 250 \mathrm{~mm}$, flow rate: $2 \mathrm{~mL}$ $\min ^{-1}$, column temperature $30{ }^{\circ} \mathrm{C}$ ). The runs were performed with a linear gradient of $\mathrm{A}(50 \mathrm{mM}$ aqueous triethylamine-acetic acid buffer $\mathrm{pH}=6.45$ ) and $\mathrm{B}$ (acetonitrile Fisher HPLC-grade): $t$ $=0 \mathrm{~min}, 5 \% \mathrm{~B}, t=15 \mathrm{~min}, 50 \% \mathrm{~B}, t=16 \mathrm{~min} 95 \% \mathrm{~B}, t=20 \mathrm{~min}$, $95 \%$ B. Radio-TLC of the ${ }^{64} \mathrm{Cu}$-labeled antibody conjugates $\left[{ }^{64} \mathrm{Cu}\right] \mathrm{Cu}-(\mathrm{NOTA})_{3}-\mathrm{C} 225$ and $\left[{ }^{64} \mathrm{Cu}\right] \mathrm{Cu}-(\mathrm{NOTA})_{3}$-C225-Cys-c-PNA were performed at ITLC-SA plates and $0.9 \%$ sodium chloride solution as mobile phase. UV/Vis measurements and hybridization studies were performed on a Specord 210 from Analytik Jena AG. To determine the concentrations of PNA-derivatives measurements carried out at $260 \mathrm{~nm}$ by $90{ }^{\circ} \mathrm{C}$ with following extinction coefficients: Cys-c-PNA $\varepsilon=197 \mu \mathrm{L} \times \mathrm{nmol}^{-1} \times \mathrm{cm}^{-1}$,

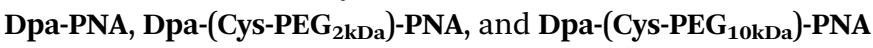
$\varepsilon=182 \mu \mathrm{L} \times \mathrm{nmol}^{-1} \times \mathrm{cm}^{-1}$. Cetuximab derivatives were measured at $280 \mathrm{~nm}$ by room temperature. The extinction coefficient was determined via UV/Vis calibration curve and linear regression analysis: $\mathbf{C 2 2 5} \varepsilon=217 \pm 14 \mu \mathrm{L} \mathrm{nmol}^{-1} \mathrm{~cm}^{-1}$.

\section{General chemistry}

General procedure for synthesis of PNAs. The synthesis of the PNAs was performed as previously reported by our groups. ${ }^{48}$ More specifically, the SPPS of PNAs was performed manually in $5 \mathrm{~mL}$ polypropylene one-way syringes equipped with a frit at the bottom. They were filled with $100 \mathrm{mg}$ of polystyrene resin beads TentaGel S RAM Lys(Boc)Fmoc $\left(0.23 \mathrm{mmol} \mathrm{g}^{-1}\right)$. The resin was swollen in DMF for $1 \mathrm{~h}$ before use. All reactions were performed on a mechanical shaker at $400 \mathrm{rpm}$ with approximately 3-4 $\mathrm{mL}$ of freshly prepared solutions in the syringes. Fmoc/Bhoc-protected PNA monomers, the Fmoc spacer (5.0 equiv., all from Link Technologies, Lanarkshire, Scotland) or cysteine were preactivated in Eppendorf tubes before every coupling step for 2 min with HATU (4.5 equiv.) in DMF, adding DIPEA and 2,6lutidine (10.0 equiv. each, $2 \mathrm{~min}$ for the $\mathrm{T}$ and $\mathrm{G}$ (Bhoc) PNA monomers and the PNA spacer, $5 \mathrm{~min}$ for the A(Bhoc)-PNAmonomer and $7 \mathrm{~min}$ for $\mathrm{C}(\mathrm{Bhoc})$-PNA-monomer). For each coupling step the resin beads were treated with the activated acid under shaking for $1.5 \mathrm{~h}$ and subsequently washed with DMF. The coupling step was monitored by the Kaiser test. Two Fmoc deprotection steps were performed with piperidine $(20 \%$, $\mathrm{v} / \mathrm{v})$ in DMF $(2+10 \mathrm{~min})$. The resin beads were then washed successively with DMF, DCM and DMF. The whole procedure (deprotection, coupling, monitoring) was repeated for every PNA monomer until the PNA sequence was completed. Before cleavage, the resin was shrunk with methanol and dried. The PNAs were then cleaved using a mixture of trifluoroacetic acidwater-triisopropylsilane $95: 2.5: 5 \mathrm{v} / \mathrm{v} / \mathrm{v}[3 \times 1.5 \mathrm{~mL}(90 \mathrm{~min}$ each)]. The resulting solutions were first evaporated to dryness before being precipitated with ice-cold ether. The solids were centrifuged, washed with ice-cold ether and finally air-dried. The obtained crude oligomers were lyophilized in acetonitrilewater, purified and analyzed with RP-HPLC, and finally characterized with ESI and/or MALDI-TOF mass spectrometry.

Cys-c-PNA (H-Cys-spacer-spacer-ataatcacataacataa-Lys- $\mathrm{NH}_{2}$ ). To obtain Cys-c-PNA, Fmoc-Cys(Trt)-OH was added to the growing PNA chain on the beads by using the same protocol as for PNA monomers (described above). The resulting Cys-c-PNA was cleaved off the resin following the general protocol shown above and purified by preparative HPLC to yield white powder. 
Characterization: ESI-MS $m / z$ 852.2 $[\mathrm{M}+6 \mathrm{H}]^{6+}, 730.8[\mathrm{M}+7 \mathrm{H}]^{7+}$, $639.4[\mathrm{M}+8 \mathrm{H}]^{8+}, 568.8[\mathrm{M}+9 \mathrm{H}]^{9+} ;$ MALDI-TOF (PAC HCCA, RP) $m / z 5108.2[\mathrm{M}+\mathrm{H}]^{1+}, 5130.2[\mathrm{M}+\mathrm{Na}]^{1+}$.

Dpa-PNA (H-Dpa-spacer-spacer-ttatgttatgtgattat-Lys-NH $\mathrm{H}_{2}$ ). To append the Dpa ligand to PNA, 4-pentynoic acid was added to the $N$-terminus of the PNA sequence according to the procedure previously reported by Gasser et al. ${ }^{48}$ Dpa (5 equiv.) and CuI (2 equiv.) dissolved in a mixture DIPEA-DMF $1: 6 \mathrm{v} / \mathrm{v}(4.207 \mathrm{~mL})$ were introduced into the syringe and the mixture was shaken overnight. The resin was thoroughly washed by DMF, DCM, ACN, EDTA $0.1 \mathrm{M}$, shaken in EDTA $0.1 \mathrm{M}$ for $2 \mathrm{~h}(3 \times)$ and washed by ACN, DCM and DMF. The product was then cleaved off the resin (see the General procedure above) and isolated by preparative HPLC as white powder. Characterization: ESI-MS $m / z 1085.2[\mathrm{M}+5 \mathrm{H}]^{5+}, 906.6[\mathrm{M}+6 \mathrm{H}]^{6+}, 775.5[\mathrm{M}+7 \mathrm{H}]^{7+}, 678.7$ $[\mathrm{M}+8 \mathrm{H}]^{8+}, 603.4[\mathrm{M}+9 \mathrm{H}]^{9+} ; 1097.9[\mathrm{M}+\mathrm{Cu}+5 \mathrm{H}]^{5+}, 915.3[\mathrm{M}+$ $\mathrm{Cu}+6 \mathrm{H}]^{6+}, 785.1[\mathrm{M}+\mathrm{Cu}+7 \mathrm{H}]^{7+}, 686.6[\mathrm{M}+\mathrm{Cu}+8 \mathrm{H}]^{8+}, 610.5[\mathrm{M}+$ $\mathrm{Cu}+9 \mathrm{H}]^{9+} ; 1066.8\left[\mathrm{M}-\operatorname{py}(\mathrm{CH})_{2}+5 \mathrm{H}\right]^{5+}, 889.0\left[\mathrm{M}-\operatorname{py}(\mathrm{CH})_{2}+\right.$ $6 \mathrm{H}]^{6+}, 762.3\left[\mathrm{M}+-\mathrm{py}(\mathrm{CH})_{2}+7 \mathrm{H}\right]^{7+}, 667.1\left[\mathrm{M}+-\mathrm{py}(\mathrm{CH})_{2}+8 \mathrm{H}\right]^{8+}$, $593.1\left[\mathrm{M}+-\mathrm{py}(\mathrm{CH})_{2}+9 \mathrm{H}\right]^{9+}$. MALDI-TOF (SA, LP) $m / z 5422.2$ $[\mathrm{M}+\mathrm{H}]^{1+}, 5444.2[\mathrm{M}+\mathrm{Na}]^{1+}, 5485.9[\mathrm{M}+\mathrm{Cu}+\mathrm{H}]^{1+}, 5393.8[\mathrm{M}-$ $\left.\operatorname{py}\left(\mathrm{CH}_{2}\right)+\mathrm{Cu}+\mathrm{H}\right]^{1+}, 5330.2\left[\mathrm{M}-\operatorname{py}\left(\mathrm{CH}_{2}\right)+\mathrm{H}\right]^{1+}$.

Dpa-Cys-PNA (H-Dpa-spacer-spacer-Cys-spacer-spacer-ttatgttatgtgattat-Lys- $\mathrm{NH}_{2}$ ). To allow PEG conjugation via Michael addition, cysteine residue was added to the PNA sequence as described above for Cys-PNA. Dpa ligand was introduced as specified above for DPA-PNA. The product was cleaved off the resin (see the General procedure) and purified by preparative HPLC to obtain white powder. Characterization: ESI-MS $\mathrm{m} / \mathrm{z}$ 831.4 $[\mathrm{M}+7 \mathrm{H}]^{7+}, 727.6[\mathrm{M}+8 \mathrm{H}]^{8+}, 647.1[\mathrm{M}+9 \mathrm{H}]^{9+}$. MALDI-TOF (SA, LP) $m / z 5815.9[\mathrm{M}+\mathrm{H}]^{1+}, 5837.8[\mathrm{M}+\mathrm{Na}]^{1+}, 5879.4[\mathrm{M}+\mathrm{Cu}$ $+\mathrm{H}]^{1+}, 5787.2\left[\mathrm{M}-\operatorname{py}\left(\mathrm{CH}_{2}\right)+\mathrm{Cu}+\mathrm{H}\right]^{1+}, 5723.7\left[\mathrm{M}-\operatorname{py}\left(\mathrm{CH}_{2}\right)+\right.$ $\mathrm{H}]^{1+}, 5745.7\left[\mathrm{M}-\mathrm{py}\left(\mathrm{CH}_{2}\right)+\mathrm{Na}\right]^{1+}$.

Dpa-(Cys-PEG $\left.\boldsymbol{G}_{\boldsymbol{x}}\right)$-PNA. Dpa-Cys-PNA and TCEP (10 equiv.) were dissolved in distilled water $(30 \mathrm{~mL})$ and shaken overnight. The reaction mixture was then lyophilized, redissolved in $10 \mathrm{mM}$ $\mathrm{HCl}$ and separated by size exclusion. The collected Dpa-Cys-PNA fractions were combined and split into two flasks $(\sim 20 \mathrm{~mL}$ each). MeO-PEG $2 \mathrm{kDa}$-maleimide (5 equiv.) or $\mathrm{MeO}-\mathrm{PEG}_{10 \mathrm{kDa}}{ }^{-}$ Maleimide ( 5 equiv.) was added and the mixture was then shaken overnight. The reaction mixtures were lyophilized, purified and analyzed with RP-HPLC and characterized by ESI and MALDI-TOF mass spectrometry.

Characterization of Dpa-(Cys-PEG 2kDa $_{\text {-PNA. MALDI-TOF }}$ (PAC HCCA, LP): a Gaussian distribution of peaks corresponding to PEG of various lengths $\left(\mathrm{PEG}_{35}\right.$ to $\left.\mathrm{PEG}_{45}\right)$ was observed; some of the most intense peaks: Dpa-PEG $\mathbf{4 2}_{\mathbf{4}}$-PNA $\mathrm{m} / \mathrm{z} 7822.2$ $[\mathrm{M}+\mathrm{H}]^{1+}$, Dpa-PEG $4 \mathbf{4 3}^{-P N A} m / z$ 7866.2 $[\mathrm{M}+\mathrm{H}]^{1+}$, Dpa-PEG D4 $^{-P N A}$ $m / z$ 7910.2 $[\mathbf{M}+\mathrm{H}]^{1+}$, Dpa-PEG ${ }_{45}$-PNA $m / z$ 7954.4 $[\mathbf{M}+\mathrm{H}]^{1+}$, DpaPEG $_{46}$-PNA $m / z$ 7998.4 $[\mathrm{M}+\mathrm{H}]^{1+}$, Dpa-PEG - $^{-P N A ~} \mathrm{~m} / \mathrm{z} 8042.5$ $[\mathrm{M}+\mathrm{H}]^{1+}$, Dpa-PEG $41^{-P N A} m / z$ 7778.1 $[\mathbf{M}+\mathrm{H}]^{1+}$, Dpa-PEG 40 -PNA $m / z$ 7734.0 $[\mathrm{M}+\mathrm{H}]^{1+}$, Dpa-PEG 39 -PNA $m / z 7690.0[\mathbf{M}+\mathrm{H}]^{1+}$, DpaPEG $_{38}$-PNA $m / z$ 7645.9 $[\mathbf{M}+\mathrm{H}]^{1+}$, Dpa-PEG ${ }_{37}$-PNA $m / z 7601.9$ $[\mathrm{M}+\mathrm{H}]^{1+}$. Corresponding $[\mathrm{M}+2 \mathrm{H}]^{2+}$ states, such as $\mathrm{m} / z 3911.6$ (Dpa-PEG $\mathbf{4 2}_{\mathbf{4}}$-PNA) were also observed.

Characterization of Dpa-(Cys-PEG 10kDa $)$-PNA. MALDI-TOF (PAC HCCA, LP) a Gaussian distribution of peaks corresponding to PEG of various lengths $\left(\mathrm{PEG}_{230}\right.$ to $\left.\mathrm{PEG}_{270}\right)$ was observed; some of most intense peaks: Dpa-PEG $\mathbf{2 4 1}_{\mathbf{2}}$-PNA $\mathrm{m} / \mathrm{z} 16588.1$ [M +

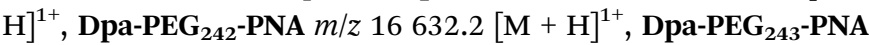
$\mathrm{m} / \mathrm{z} 16676.2[\mathrm{M}+\mathrm{H}]^{1+}$, Dpa-PEG 244 -PNA $m / z 16720.3[\mathrm{M}+\mathrm{H}]^{1+}$, Dpa-PEG ${ }_{245}$-PNA $m / z 16764.3[\mathrm{M}+\mathrm{H}]^{1+}$, Dpa-PEG 246 -PNA $\mathrm{m} / \mathrm{z}$ $16808.4[\mathrm{M}+\mathrm{H}]^{1+}$, Dpa-PEG 247 -PNA $m / z 16852.4[\mathrm{M}+\mathrm{H}]^{1+}$, Dpa-PEG $_{248}$-PNA $m / z 16896.5[\mathrm{M}+\mathrm{H}]^{1+}$, Dpa-PEG 249 -PNA $\mathrm{m} / \mathrm{z}$ $16940.1[\mathrm{M}+\mathrm{H}]^{1+}$, Dpa-PEG 250 -PNA $m / z 16984.6[\mathrm{M}+\mathrm{H}]^{1+}$, Dpa-PEG $_{251}$-PNA $m / z 17028.6[\mathrm{M}+\mathrm{H}]^{1+}$, Dpa-PEG 252 -PNA $\mathrm{m} / \mathrm{z}$ $17072.7[\mathrm{M}+\mathrm{H}]^{1+}$, Dpa-PEG ${ }_{253}$-PNA $m / z 17116.7[\mathrm{M}+\mathrm{H}]^{1+}$, Dpa-PEG $_{254}$-PNA $m / z 17160.8[\mathrm{M}+\mathrm{H}]^{1+}$, Dpa-PEG 255 -PNA $\mathrm{m} / \mathrm{z}$

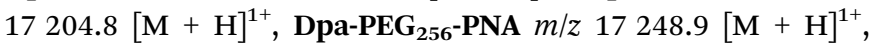
Dpa-PEG $_{257}$-PNA $m / z 17292.9[\mathrm{M}+\mathrm{H}]^{1+}$, Dpa-PEG 258 -PNA $\mathrm{m} / \mathrm{z}$ $17336.9[\mathrm{M}+\mathrm{H}]^{1+}$, Dpa-PEG 259 -PNA $m / z 17381.0[\mathrm{M}+\mathrm{H}]^{1+}$, Dpa-PEG $_{260}$-PNA $m / z 17425.1[\mathrm{M}+\mathrm{H}]^{1+}$. Corresponding $[\mathrm{M}+$ $2 \mathrm{H}]^{2+}$ states, such as $m / z 8382.7$ (Dpa-PEG 245 $^{- \text {PNA) were also }}$ observed.

Polydispersity index (PDI) calculation for PEGylated PNAs. PDI index was calculated using the following formula:

$$
\mathrm{PDI}=M_{\mathrm{w}} / M_{\mathrm{n}}
$$

where $M_{\mathrm{w}}$ is weight average molecular weight defined as

$$
M_{\mathrm{w}}=\frac{\sum_{i} N_{i} M_{i}^{2}}{\sum_{i} N_{i} M_{i}}
$$

and $M_{\mathrm{n}}$ is number average molecular weight defined as

$$
M_{\mathrm{w}}=\frac{\sum_{i} N_{i} M_{i}}{\sum_{i} N_{i} M_{i}}
$$

where $M_{i}$ is mass of a polymer of a certain length and $N_{i}$ is the amount of this polymer present.

$M_{\mathrm{n}}$ and $M_{\mathrm{w}}$ were estimated from MALDI spectra. As PEG polymers used for synthesis had PDI $<1.1$ and PNA was monodisperse, PDI of PEGylated PNAs was expected to be <1.1. Therefore, no mass discrimination effect should have interfered, so $N_{i}$ was assumed to be proportional to peak intensity in MALDI spectra. Calculated PDIs corresponded to those of PEG starting material.

\section{Bioconjugation chemistry}

(NOTA) ${ }_{3}$-C225. $3 \mathrm{~mL}$ of Erbitux ${ }^{\circledR}$ stock solution $\left(5 \mathrm{mg} \mathrm{mL}^{-1}\right)$ for infusion purposes were added to a Jumbosep ${ }^{\mathrm{TM}}$ centrifugal devices (30 kDa cut-off) containing $55 \mathrm{~mL}$ of $50 \mathrm{mM}$ sodium bicarbonate saline buffer ( $\mathrm{pH}$ 6.4). In order to completely remove infusion solution by sodium bicarbonate saline buffer, the procedure of centrifugal filtration was carried out 6 times $\left(2500 \mathrm{~min}^{-1}, 60 \mathrm{~min}, 10^{\circ} \mathrm{C}\right.$ ). The resulting Erbitux ${ }^{\circledR}$ solution ( $\sim 6 \mathrm{~mL}$ ) was finally concentrated to circa $1.2 \mathrm{~mL}$ by application of Macrosep ${ }^{\mathrm{TM}}$ Advance centrifugal device (30 kDa cut-off; $2500 \mathrm{~min}^{-1}, 90 \mathrm{~min}, 10^{\circ} \mathrm{C}$ ). The concentrated Erbitux® solution was transferred into a Teflon-coated plastic vial and $10.2 \mathrm{mg}$ of $p$-SCN-Bn-NOTA $\times 3 \mathrm{HCl}(18.2 \mu \mathrm{mol})$ dissolved in $2.130 \mathrm{~mL}$ $50 \mathrm{mM}$ HEPES buffer $(\mathrm{pH} 7.2)$ were added in aliquots. The 
molar ration of the NOTA derivative to Erbitux ${ }^{\circledR}$ was 185 : 1 with a resulting $\mathrm{pH}$ value of 6.9. The reaction mixture was left for 22 $\mathrm{h}$ at room temperature and the vial was swirled occasionally.

The reaction mixture was worked up by centrifugal filtration for 6 times (Jumbosep ${ }^{\mathrm{TM}}$ centrifugal devices; $30 \mathrm{kDa}$ cut-off; $50 \mathrm{mM}$ sodium bicarbonate saline buffer; $\mathrm{pH}$ 6.4; $2500 \mathrm{~min}^{-1}$, $60 \mathrm{~min}, 10{ }^{\circ} \mathrm{C}$ ). Finally, the product solution was further concentrated to circa $1.0 \mathrm{~mL}$ by Macrosep ${ }^{\mathrm{TM}}$ Advance centrifugal device (30 kDa cut-off; $2500 \mathrm{~min}^{-1}$, $90 \mathrm{~min}, 10{ }^{\circ} \mathrm{C}$ ). The recovery of the antibody was almost quantitatively ( $98 \%$ by UV/Vis measurement). This value was assumed as yield. MALDITOF (SA, LP): Gaussian distribution of peaks was observed; most intense peaks: $m / z 154106[\mathrm{M}+\mathrm{H}]^{1+}, m / z 77184[\mathrm{M}+$ $2 \mathrm{H}]^{2+}$.

(NOTA) ${ }_{3}$-C225-mal. A solution of $50 \mathrm{mM}$ sodium bicarbonate saline ( $\mathrm{pH} 6.4 ; 0.9 \% \mathrm{w} / \mathrm{w} \mathrm{NaCl}$ ) containing (NOTA) ${ }_{3}$-C225 (app. 95-100 nmol) was diluted with phosphate buffer $(\mathrm{pH} \mathrm{6.2)}$ to a final volume of $3.400 \mathrm{~mL}$ and $1000 \mathrm{nmol} \mathrm{4-maleimido-butyric}$ acid $N$-succinimidyl ester $(0.28 \mathrm{mg})$ in $50 \mu \mathrm{L}$ DMSO were added. The reaction mixture was left for $5 \mathrm{~h}$ at room temperature and swirled occasionally. The resulting (NOTA) $_{3}$-C225-mal was subsequently purified by centrifugal filtration for 6 times (Jumbosep $^{\mathrm{TM}}$ centrifugal devices; $30 \mathrm{kDa}$ cut-off; phosphate buffer pH $6.4 ; 2500 \mathrm{~min}^{-1}, 60 \mathrm{~min}, 10^{\circ} \mathrm{C}$ ). Finally, the product solution was further concentrated to circa $2.0 \mathrm{~mL}$ by Macrosep ${ }^{\mathrm{TM}}$ Advance centrifugal device (30 kDa cut-off; $2500 \mathrm{~min}^{-1}$, $160 \mathrm{~min}, 10^{\circ} \mathrm{C}$ ). The recovery of the antibody was $85 \%$ (UV/Vis measurement). This value was assumed as yield. MALDI-TOF (SA, LP): Gaussian distribution of peaks was observed; most intense peaks: $m / z 155477[\mathrm{M}+\mathrm{H}]^{1+}, m / z 77984[\mathrm{M}+2 \mathrm{H}]^{2+}$.

(NOTA) $)_{3}$-C225-Cys-c-PNA. $960 \mathrm{nmol}$ of Cys-c-PNA $(5110 \mathrm{~g}$ $\mathrm{mol}^{-1}$ ) were dissolved in a mixture of $1000 \mu \mathrm{L}$ of phosphate buffer and $1000 \mu \mathrm{L}$ DMSO. This solution was added in aliquots to a Teflon-coated plastic vial containing the previously concentrated $2 \mathrm{~mL}$ phosphate buffer of (NOTA) $)_{3}$-C225-mal. The molar ratio of Cys-c-PNA derivative to (NOTA) , $_{3}$-C225-mal was app. $11: 1$. The reaction mixture was left for 4 days at room temperature and the vial was swirled occasionally. The high viscosity of DMSO containing solution led to extraordinary slow centrifugal filtration (Macrosep ${ }^{\mathrm{TM}}$ Advance device, $30 \mathrm{kDa}$ cutoff). The addition of $12 \mathrm{~mL}$ phosphate buffer was required to dilute the reaction mixture, which also led to precipitation of non-reacted Cys-c-PNA. Subsequently, the solution was transferred into several Protein low-bind tubes from Eppendorf, cooled to $10^{\circ} \mathrm{C}$ for $2 \mathrm{~h}$, and centrifuged for $60 \mathrm{~min}\left(2500 \mathrm{~min}^{-1}\right.$, $10{ }^{\circ} \mathrm{C}$ ). The resulting clear supernatant was transferred carefully into a Jumbosep ${ }^{\mathrm{TM}}$ device. After adding $40 \mathrm{~mL}$ of phosphate buffer the diluted reaction mixture was purified by centrifugal filtration. The purification using Jumbosep ${ }^{\mathrm{TM}}$ devices was performed 6 times. Finally, the product solution was further concentrated to circa $1.0 \mathrm{~mL}$ by Macrosep ${ }^{\mathrm{TM}}$ Advance centrifugal device (30 kDa cut-off; $2500 \mathrm{~min}^{-1}$, $90 \mathrm{~min}, 10^{\circ} \mathrm{C}$ ). MALDITOF (SA, LP): Gaussian distribution of peaks was observed; most intense peaks: $m / z 168614.1[\mathrm{M}+\mathrm{H}]^{1+}, m / z 86022[\mathrm{M}+$ $2 \mathrm{H}]^{2+}$.

The number of bound Cys-c-PNA to cetuximab was also spectrophotometrically determined by measuring the absorbance at different wavelengths. ${ }^{92-94}$ The maximum absorbance of cetuximab was found to be at $280 \mathrm{~nm}$ and of Cys-c-PNA at $260 \mathrm{~nm}$. Assuming that the conjugation of Cys-c-PNA to cetuximab will not influence the extinction coefficients of the individual compounds Lambert-Beer law were formulated at $260 \mathrm{~nm}$ and $280 \mathrm{~nm}$. The extinction coefficients of cetuximab and Cys-c-PNA were determined via UV/Vis calibration curves and linear regression analysis: $\varepsilon_{\text {cetuximab } 280 \mathrm{~nm}}=217 \pm 14$ $\mu \mathrm{L} \mathrm{nmol}{ }^{-1} \mathrm{~cm}^{-1}, \varepsilon_{\text {cetuximab } 260 \mathrm{~nm}}=97 \pm 6 \mu \mathrm{L} \mathrm{nmol}^{-1} \mathrm{~cm}^{-1}$, $\varepsilon_{\text {Cys-c-PNA } 280 \mathrm{~nm}}=114 \pm 4 \mu \mathrm{L} \mathrm{nmol}^{-1} \mathrm{~cm}^{-1}$ and $\varepsilon_{\text {Cys-c-PNA } 260 \mathrm{~nm}}=$ $192 \pm 6 \mu \mathrm{L} \mathrm{nmol}^{-1} \mathrm{~cm}^{-1}$. Based on the $260 \mathrm{~nm} / 280 \mathrm{~nm}$ absorbance ratio, the conjugation degree can be calculated with following equation:

$$
n=\frac{E_{280 \mathrm{~nm}} \times \varepsilon_{\mathrm{C} 225260 \mathrm{~nm}}-E_{260 \mathrm{~nm}} \times \varepsilon_{\mathrm{C} 225280 \mathrm{~nm}}}{E_{260 \mathrm{~nm}} \times \varepsilon_{\text {Cys-c-PNA } 280 \mathrm{~nm}}-E_{280 \mathrm{~nm}} \times \varepsilon_{\text {Cys-c-PNA } 260 \mathrm{~nm}}}
$$

\section{Radiochemistry}

${ }^{99} \mathrm{~m}$ Tc-labeling. $1.5-2.5 \mathrm{~mL}$ of freshly eluted $\left[{ }^{99 \mathrm{~m}} \mathrm{Tc}\right] \mathrm{TcO}_{4}{ }^{-}$ solution (400-1450 MBq) were injected into IsoLink® vial. The resulting mixture was heated to $100{ }^{\circ} \mathrm{C}$ for $30 \mathrm{~min}$. In order to prevent pressure issues and to concentrate the resulting $\left[{ }^{99 \mathrm{~m}} \mathrm{Tc}\right]$ $\mathrm{Tc}(\mathrm{CO})_{3}\left(\mathrm{H}_{2} \mathrm{O}\right)_{3}{ }^{+}$solution, a syringe needle was inserted through the rubber plug of the vial. The needle was removed before the mixture was cooled to room temperature.

For each radiolabeling experiment $10 \mathrm{nmol}$ of particular Dpa-PNA derivative from stock solution diluted in $400 \mu \mathrm{L}$ of phosphate buffer (pH 5.4) were used. The labeling tube containing the PNA solution was gently flushed with argon for 5 min. Subsequently, approximately $400 \mu \mathrm{L}\left[{ }^{99 \mathrm{~m}} \mathrm{Tc}\right] \mathrm{Tc}(\mathrm{CO})_{3}\left(\mathrm{H}_{2}-\right.$ $\mathrm{O})_{3}{ }^{+}$kit solution (250-580 MBq) were added. The $\mathrm{pH}$ value of the radiolabeling mixture was tested by a triple zone $\mathrm{pH}$-paper (Tritest $\mathrm{pH}$ 1-11). Optimal $\mathrm{pH}$ for radiolabeling ranges from 7 to 8. Occasionally, the $\mathrm{pH}$ value had to be adjusted by addition of further phosphate buffer ( $\mathrm{pH} 5.4$ or 8.2). The mixture was heated to $70{ }^{\circ} \mathrm{C}$ for $40 \mathrm{~min}$ and cooled to room temperature. The radiochemical yield (rcy) was determined by radio-HPLC. For HPLC injection purposes, $10 \mu \mathrm{L}$ of labeling mixture were added to $90 \mu \mathrm{L}$ of HPLC solvent A. For all radiolabeling experiments rcy of $>95 \%$ determined from reaction mixtures $(n=19)$ were obtained. Decay corrected effective specific activities of up to $58 \mathrm{GBq} \mu \mathrm{mol}^{-1}$ were achieved. For in vivo studies (biodistribution and SPECT imaging) the radiolabeling mixtures were concentrated and re-buffered (sterile PBS) by centrifugal filtration (13 $200 \mathrm{~min}^{-1} ; 20 \mathrm{~min} ; 25^{\circ} \mathrm{C}$; recovery of activity 70$80 \%)$. Centrifugal filtration was applied for purification purposes, if insufficient rcy $(<95 \%)$ occurred. A typical volume of radiolabeled Dpa-PNA derivatives was $150-250 \mu \mathrm{L}$ sterile phosphate buffered saline (PBS). Characterization: Radio-HPLC $t_{\mathrm{R}}:{ }^{99 \mathrm{~m}} \mathrm{TcO}_{4}{ }^{-} 3.0 \mathrm{~min} ;\left[{ }^{99 \mathrm{~m}} \mathrm{Tc}\left(\mathrm{H}_{2} \mathrm{O}\right)_{3}(\mathrm{CO})_{3}\right]^{+}$5.0-6.0 min; DpaPNA $10.5 \mathrm{~min}$; Dpa-(Cys-PEG $2 \mathrm{kDa})$-PNA $12.0 \mathrm{~min}$; Dpa-(CysPEG $_{\text {10kDa}}$ )-PNA $12.9 \mathrm{~min}$.

${ }^{64} \mathrm{Cu}$-labeling. $3 \mathrm{nmol}$ of antibody stock solution of (NOTA) ${ }_{3}$ -

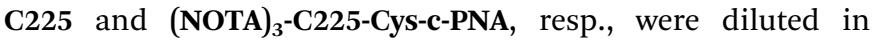
$200 \mu \mathrm{L}$ MES buffer $(1 \mathrm{M}, \mathrm{pH}=6.0) .50 \mathrm{MBq}$ aliquots of $\left[{ }^{64} \mathrm{Cu}\right]$ 
$\mathrm{CuCl}_{2}$ dissolved in $0.01 \mathrm{M} \mathrm{HCl}$ were added to $200 \mu \mathrm{L}$ MES buffer $(1 \mathrm{M}, \mathrm{pH}=6.0)$ and then mixed with the antibody solution. The reaction mixture was incubated in a thermomixer for $35 \mathrm{~min}$ at $30{ }^{\circ} \mathrm{C}$ and the vial was swirled occasionally by manual stimulation. Afterwards, $4 \mu \mathrm{L}$ of an aqueous EDTA solution $(0.75 \mathrm{mM})$ were added to remove non-specific bound ${ }^{64} \mathrm{Cu}$. After a reaction time of $10 \mathrm{~min}$ at room temperature the product mixture was checked by radio TLC for complete complexation of $\left[{ }^{64} \mathrm{Cu}\right] \mathrm{Cu}^{2+}$. Rcy of $>99 \%$ were achieved without any further purification (radiochemical purity >99\%). $\left[{ }^{64} \mathbf{C u}\right] \mathbf{C u}-(\text { NOTA) })_{3}-\mathbf{C 2 2 5}$ and $\left[{ }^{64} \mathbf{C u}\right] \mathrm{Cu}$-(NOTA) ${ }_{3}$-C225-Cys-c-PNA could be labeled with effective specific activities of up to $16.6 \mathrm{GBq} \mu \mathrm{mol}^{-1}$. Characterization: Radio-TLC $\left[{ }^{64} \mathrm{Cu}\right] \mathrm{Cu}-(\mathrm{NOTA})_{3}-\mathrm{C} 225 \quad R_{\mathrm{f}}=0,\left[{ }^{64} \mathrm{Cu}\right] \mathrm{Cu}-$ (NOTA) $)_{3}$-C225-Cys-c-PNA $R_{\mathrm{f}}=0$.

\section{Hybridization studies}

Self-complementarity. UV/Vis cuvettes were filled with particular PNA probe at room temperature. After cooling to $5{ }^{\circ} \mathrm{C}$ the samples were heated to $95{ }^{\circ} \mathrm{C}$.

Melting curves $(\boldsymbol{n}=2)$. For hybridization studies equimolar amounts of $3 \mu \mathrm{M}$ stock solutions of each Dpa-PNA derivatives and complementary Cys-c-PNA were filled into the cuvette. For the first step the single probes were heated up to $95{ }^{\circ} \mathrm{C}$ for $5 \mathrm{~min}$ to induce complete de-hybridization. The second step included cooling to $5{ }^{\circ} \mathrm{C}$ to achieve a fully hybridization with a gradient of $2{ }^{\circ} \mathrm{C} \min ^{-1}$. During the third step the samples were heated with a gradient of $2{ }^{\circ} \mathrm{C} \min ^{-1}$ from $5{ }^{\circ} \mathrm{C}$ to $95{ }^{\circ} \mathrm{C}$. The data points were analyzed with a polynomial fit ( $9^{\text {th }}$ order) by the analysis software Origin Pro 8.6. The melting point $T_{\mathrm{M}}$ is equal to the maximum of the $1^{\text {st }}$ differentiation of the sigmoid shaped melting curve.

\section{Biological studies}

Determination of $\log D_{\mathrm{o} / \mathrm{w}}$ at $25 \pm 1{ }^{\circ} \mathrm{C}$. Information on the lipophilicity of ${ }^{99 \mathrm{~m}}$ Tc-labeled Dpa-PNA, Dpa-(Cys-PEG $\left.2 \mathbf{k D a}\right)-\mathbf{P N A}$

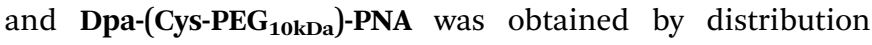
experiments in a water/1-octanol system. All radiolabeled PNA derivatives were isolated by HPLC in radiochemical purity of $>98 \%$. Aliquots of $250 \mathrm{kBq}$ were added to phosphate buffered saline with $\mathrm{pH}$ values of 7.2, 7.4 and 7.6 reaching a total volume of $500 \mu \mathrm{L}$ in $2 \mathrm{~mL}$ microcentrifuge tubes. To this solution, $500 \mu \mathrm{L}$ of 1 -octanol were added and the two phases were agitated in a thermomixer for $30 \mathrm{~min}$ at $(25 \pm 1){ }^{\circ} \mathrm{C}$. After centrifugation of samples, aqueous and organic phases were separated and aliquots of both phases were measured using an automated gamma counter (PerkinElmer Life and Analytical Sciences). Each value was recorded as triplet.

Cell culture. For binding studies, two different adherent human tumor cell lines were used: the epidermoid carcinoma cell line A431 (ATCC@ Number: CRL-1555) and the squamous cell carcinoma cell line FaDu (ATCC® number: HTB-43). All cells were cultured as previously reported..$^{87,103}$

Binding affinity of $\left[{ }^{64} \mathrm{Cu}\right] \mathrm{Cu}-(\mathrm{NOTA})_{3}-\mathrm{C} 225-\mathrm{Cys}-\mathrm{c}-\mathrm{PNA}$ and $\left[{ }^{64} \mathrm{Cu}\right] \mathrm{Cu}-(\mathrm{NOTA})_{3}-\mathrm{C} 225$ to human EGFR-presenting cells. In vitro binding studies of $\left[{ }^{64} \mathrm{Cu}\right] \mathrm{Cu}-(\mathrm{NOTA})_{3}$-C225-Cys-c-PNA and $\left[{ }^{64} \mathbf{C u}\right] \mathrm{Cu}-(\mathrm{NOTA})_{3}-\mathbf{C 2 2 5}$ were performed as previously reported by Zarschler et al. ${ }^{\mathbf{1 0 3}}$ with slight modifications. Briefly, cells were plated in 24 well cell culture microplates (Greiner Bio-One) at a density of $1 \times 10^{5}$ cells per $0.5 \mathrm{~mL}$ per well and incubated for $48 \mathrm{~h}$ prior to addition of radiolabeled cetuximab conjugates. After $48 \mathrm{~h}$, cells were preincubated for $30 \mathrm{~min}$ at $4{ }^{\circ} \mathrm{C}$ before the addition of different concentrations of radiolabeled cetuximab conjugates ranging from $0.1 \mathrm{nM}$ to $100 \mathrm{nM}$. The cell culture microplates were further incubated for $60 \mathrm{~min}$ at $4{ }^{\circ} \mathrm{C}$. Following treatment with radiolabeled cetuximab conjugates, cells were washed three times with PBS in order to ensure removal of loosely attached proteins from the cellular membrane. Finally, cell lysis was achieved by the addition of $1 \%$ SDS/0.1 M NaOH and incubation for $30 \mathrm{~min}$ at room temperature with vigorous shaking. The radioactivity in the cell extracts was quantified using an automated gamma counter (PerkinElmer Life and Analytical Sciences). Total protein concentration in cell extracts was determined colorimetrically with the $D C$ Protein Assay (Bio-Rad Laboratories) according to the manufacture's microplate assay protocol using bovine serum albumin as protein standard.

Animal husbandry. The local animal research committee at the Landesdirektion Dresden approved the animal facilities and the experiments according to institutional guidelines and the German animal welfare regulations. Wistar rats (Wistar Unilever, HsdCpb: Wu, Harlan Winkelmann $\mathrm{GmbH}$, Borchen, Germany) and mice (NMRI, nu/nu) were housed at $26 \pm 2{ }^{\circ} \mathrm{C}$. The received standard food and tap water ad libitum.

Biodistribution studies in Wistar rats and tumor mice. Wistar rats with a mean body weight $124 \pm 25 \mathrm{~g}$ of 55 animals and female NMRI nu/nu tumor mice with a body weight $32 \pm$ $2.5 \mathrm{~g}$ of 8 animals were used. Animals were anesthetized with desfluran (Suprane, Baxter, Unterschleißheim, Germany) initially with $10 \%$ in a $30 \%$ oxygen air mixture. The radiotracer $(333 \pm 66 \mathrm{kBq}$ in $0.5 \mathrm{~mL})$ was injected into a lateral tail vein and the animals were recovered. The injected dose was calculated from the activities of the syringes before and after the injection. After 5 and $60 \mathrm{~min}$ for rats and $24 \mathrm{~h}$ for tumor mice, animals were sacrificed under anesthesia. Blood was obtained by heart puncture and the organs and tissues of interest were removed and weighed and the radioactivity was determined using an automated NaI ( $\mathrm{Tl}$ ) well counter Wallac 1470 Wizard (Perkin Elmer Lifescience). The percentage of injected dose of organ (\% ID) was calculated for organs that could be completely extracted and the standardized uptake value (SUV) was calculated according

$$
\text { SUV }=\frac{\text { tissue activity } \times \text { body weight }}{\text { injected activity } \times \text { tissue weight }}
$$

The activity amounts in the urine were calculated as difference between the injected dose and the recovery from all individual organs, tissues, blood and carcass.

Metabolic profiling. To evaluate the kinetics and metabolism of [ $\left.{ }^{{ }^{99}} \mathbf{T c}\right]\left(\right.$ Tc-Dpa)-(Cys-PEG $\left.{ }_{10 k D a}\right)-P N A$ in arterial rat blood, rats were anesthetized with desfluran and a catheter was set into the right femuralis. After radiotracer i.v. injection in a lateral tail vein were samples of arterial blood withdrawn and the blood 
plasma was analyzed for [ $\left.{ }^{99 \mathbf{m}} \mathbf{T c}\right](\mathbf{T c}-\mathrm{Dpa})-(\mathrm{Cys}-\mathbf{P E G}-\mathbf{1 0 k D a})-\mathbf{P N A}$ content by radio-HPLC. The corresponding supernatants were analyzed by radio-HPLC.

SPECT of Wistar rats and tumor mice in pretargeting trial. Wistar rats (body weight $140 \pm 51 \mathrm{~g}$ ) were under desfluran anesthesia injected in a lateral tail vein with $\left[{ }^{\mathbf{9 9 m}} \mathbf{T c}\right]$ (Tc-Dpa)-

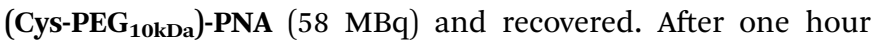
were the rats anesthetized, in the imaging bed positioned and in the NanoScanSPECT/CT imaged. CT was carried out in the NanoScan PET/CT. The DICOM image volume data were processed with InterView (Mediso, Budapest, Hungary) or converted to Siemens ECAT7 format for further processing with Rover software (ROI Visualization, Evaluation and Image Registration, $A B X$ Radeberg, Germany). A431 human squamous carcinoma cells (Sigma Aldrich, 85090402-1VL) were subcutaneously inoculated in female NMRI nu/nu mice. $2 \times 10^{6}$ cells in $100 \mu \mathrm{L}$ PBS were subcutaneously injected in the right thigh. Mice were studied when the tumors reached a size of 8 and $13 \mathrm{~mm}$. The mice with A431 tumors were intravenously injected with 4 nmol (NOTA) $)_{3}$-C225-Cys-c-PNA. At the next day, $45 \mathrm{MBq}$ of $\left[{ }^{{ }^{99 m}} \mathbf{T c}\right]($ Tc-Dpa)-(Cys-PEG 10kDa -PNA were intravenously injected and imaged $1 \mathrm{~h}$ and $20 \mathrm{~h}$ later using NanoScan SPECT. CT was carried out in NanoScan PET/CT. The image processing was carried out as described above.

Statistics. The calculations and statistics were carried out with InterView (Mediso, Hungary), ROVER (ABX GmbH. Germany), $\mathrm{R}$ (A language and environment for statistical computing, R Foundation for Statistical Computing, Vienna, Austria. ISBN 3-900051-07-0, URL http://www.R-project.org.) and GraphPad Prism version 5.00 for Windows (GraphPad Software, San Diego California USA, http://www.graphpad.com).

\section{Acknowledgements}

We thank Karin Landrock for excellent technical assistance. This work was financially supported by the Swiss National Science Foundation (Professorships no. PP00P2_133568133568 and PP00P2PP00P2_157545157545 as well as Research Grants no. 200021_129910 and no. 200020_146776 to G.G), the University of Zurich (G.G), the Stiftung für Wissenschaftliche Forschung of the University of Zurich (G.G.), the Helmholtz Virtual Institute NanoTracking (Agreement no. VH-VI-421), the Research Department Interfacial Systems Chemistry at Ruhr University Bochum (N.M.-N.) and the COST Action CM1105 (N.M.-N and G.G.). This study is part of a research initiative Technologie und Medizin - Multimodale Bildgebung zur Aufklärung des in-vivo-Verhaltens von polymeren Biomaterialien of the Helmholtz-Portfoliothema.

\section{References}

1 J. Barbet, M. Bardies, M. Bourgeois, J. F. Chatal, M. Cherel, F. Davodeau, A. Faivre-Chauvet, J. F. Gestin and F. KraeberBodere, Methods Mol. Biol., 2012, 907, 681-697.

2 I. Navarro-Teulon, C. Lozza, A. Pelegrin, E. Vives and J. P. Pouget, Immunotherapy, 2013, 5, 467-487.
3 D. M. Goldenberg and R. M. Sharkey, Expert Opin. Biol. Ther., 2012, 12, 1173-1190.

4 R. K. Jain, J. Natl. Cancer Inst., 1989, 81, 570-576.

5 M. A. Tabrizi, C. M. Tseng and L. K. Roskos, Drug Discovery Today, 2006, 11, 81-88.

6 S. M. Knowles and A. M. Wu, J. Clin. Oncol., 2012, 30, 38843892.

7 I. Vaneycken, M. D'Huyvetter, S. Hernot, J. De Vos, C. Xavier, N. Devoogdt, V. Caveliers and T. Lahoutte, Curr. Opin. Biotechnol., 2011, 22, 877-881.

8 P. Carter, Nat. Rev. Cancer, 2001, 1, 118-129.

9 R. M. Sharkey and D. M. Goldenberg, Immunotherapy, 2011, 3, 349-370.

10 S. J. Goldsmith, Semin. Nucl. Med., 2010, 40, 122-135.

11 F. Kyle and R. Pettengell, Targeted Oncol., 2007, 2, 173-179. 12 E. Frampas, C. Rousseau, C. Bodet-Milin, J. Barbet, J. F. Chatal and F. Kraeber-Bodere, Front. Oncol., 2013, 3, 159.

13 R. M. Sharkey, H. Karacay, T. M. Cardillo, C. H. Chang, W. J. McBride, E. A. Rossi, I. D. Horak and D. M. Goldenberg, Clin. Cancer Res., 2005, 11, 7109s-7121s. 14 D. M. Goldenberg, R. M. Sharkey, G. Paganelli, J. Barbet and J. F. Chatal, J. Clin. Oncol., 2006, 24, 823-834.

15 R. M. Sharkey, C. H. Chang, E. A. Rossi, W. J. McBride and D. M. Goldenberg, Tumor Biol., 2012, 33, 591-600.

16 D. J. Hnatowich, F. Virzi and M. Rusckowski, J. Nucl. Med., 1987, 28, 1294-1302.

17 S. J. Knox, M. L. Goris, M. Tempero, P. L. Weiden, L. Gentner, H. Breitz, G. P. Adams, D. Axworthy, S. Gaffigan, K. Bryan, D. R. Fisher, D. Colcher, I. D. Horak and L. M. Weiner, Clin. Cancer Res., 2000, 6, 406-414.

18 S. Shen, A. Forero, A. F. LoBuglio, H. Breitz, M. B. Khazaeli, D. R. Fisher, W. Wang and R. F. Meredith, J. Nucl. Med., 2005, 46, 642-651.

19 C. Grana, M. Chinol, C. Robertson, C. Mazzetta, M. Bartolomei, C. De Cicco, M. Fiorenza, M. Gatti, P. Caliceti and G. Paganelli, Br. J. Cancer, 2002, 86, 207-212.

20 E. Gautherot, J. Bouhou, J. M. Le Doussal, C. Manetti, M. Martin, E. Rouvier and J. Barbet, Cancer, 1997, 80, 2618-2623.

21 J. M. Le Doussal, A. Chetanneau, A. Gruaz-Guyon, M. Martin, E. Gautherot, P. A. Lehur, J. F. Chatal, M. Delaage and J. Barbet, J. Nucl. Med., 1993, 34, 1662-1671.

22 E. Janevik-Ivanovska, E. Gautherot, M. Hillairet de Boisferon, M. Cohen, G. Milhaud, A. Tartar, W. Rostene, J. Barbet and A. Gruaz-Guyon, Bioconjugate Chem., 1997, 8, 526-533.

23 R. M. Sharkey, W. J. McBride, H. Karacay, K. Chang, G. L. Griffiths, H. J. Hansen and D. M. Goldenberg, Cancer Res., 2003, 63, 354-363.

24 R. M. Sharkey, H. Karacay, W. J. McBride, E. A. Rossi, C. H. Chang and D. M. Goldenberg, Clin. Cancer Res., 2007, 13, 5577s-5585s.

25 F. Kraeber-Bodere, S. Bardet, C. A. Hoefnagel, M. R. Vieira, J. P. Vuillez, A. Murat, T. C. Ferreira, M. Bardies, L. Ferrer, I. Resche, E. Gautherot, E. Rouvier, J. Barbet and J. F. Chatal, Clin. Cancer Res., 1999, 5, 3190s-3198s. 
26 F. Kraeber-Bodere, C. Rousseau, C. Bodet-Milin, L. Ferrer, A. Faivre-Chauvet, L. Campion, J. P. Vuillez, A. Devillers, C. H. Chang, D. M. Goldenberg, J. F. Chatal and J. Barbet, J. Nucl. Med., 2006, 47, 247-255.

27 R. Schoffelen, O. C. Boerman, D. M. Goldenberg, R. M. Sharkey, C. M. van Herpen, G. M. Franssen, W. J. McBride, C. H. Chang, E. A. Rossi, W. T. van der Graaf and W. J. Oyen, Br. J. Cancer, 2013, 109, 934-942.

28 G. Liu, K. Mang'era, N. Liu, S. Gupta, M. Rusckowski and D. J. Hnatowich, J. Nucl. Med., 2002, 43, 384-391.

29 G. Liu, S. Dou, Y. Liu, Y. Wang, M. Rusckowski and D. J. Hnatowich, Bioconjugate Chem., 2011, 22, 2539-2545.

30 G. Liu, S. Dou, S. Baker, A. Akalin, D. Cheng, L. Chen, M. Rusckowski and D. J. Hnatowich, Cancer Biol. Ther., 2010, 10, 767-774.

31 G. Liu, C. Liu, S. Zhang, J. He, N. Liu, S. Gupta, M. Rusckowski and D. J. Hnatowich, Nucl. Med. Commun., 2003, 24, 697-705.

32 G. Mardirossian, K. Lei, M. Rusckowski, F. Chang, T. Qu, M. Egholm and D. J. Hnatowich, J. Nucl. Med., 1997, 38, 907-913.

33 M. Rusckowski, T. Qu, F. Chang and D. J. Hnatowich, Cancer, 1997, 80, 2699-2705.

34 Y. Wang, F. Chang, Y. Zhang, N. Liu, G. Liu, S. Gupta, M. Rusckowski and D. J. Hnatowich, Bioconjugate Chem., 2001, 12, 807-816.

35 D. M. Goldenberg, C. H. Chang, E. A. Rossi, W. J. McBride and R. M. Sharkey, Theranostics, 2012, 2, 523-540.

36 R. Rossin, S. M. van Duijnhoven, T. Lappchen, S. M. van den Bosch and M. S. Robillard, Mol. Pharmaceutics, 2014, 11, 3090-3096.

37 T. Reiner and B. M. Zeglis, J. Labelled Compd. Radiopharm., 2014, 57, 285-290.

38 T. Reiner, J. S. Lewis and B. M. Zeglis, J. Visualized Exp., 2015, e52335.

39 F. C. van de Watering, M. Rijpkema, M. Robillard, W. J. Oyen and O. C. Boerman, Front. Med., 2014, 1, 44.

40 J. Summerton and D. Weller, Antisense Nucleic Acid Drug Dev., 1997, 7, 187-195.

41 K. O. Mang'era, G. Liu, W. Yi, Y. Zhang, N. Liu, S. Gupta, M. Rusckowski and D. J. Hnatowich, Eur. J. Nucl. Med. Mol. Imaging, 2001, 28, 1682-1689.

42 M. R. Lewis and F. Jia, J. Cell. Biochem., 2003, 90, 464-472. 43 S. Scarfi, M. Giovine, R. Pintus, E. Millo, E. Clavarino, M. Pozzolini, L. Sturla, R. P. Stock, U. Benatti and G. Damonte, Biotechnol. Appl. Biochem., 2003, 38, 61-69.

44 J. Segura, C. Fillat, D. Andreu, J. Llop, O. Millan, B. G. de la Torre, Z. Nikolovski, V. Gomez, N. Andreu, A. Pinyot, R. Castelo, J. D. Gispert and J. A. Pascual, Ther. Drug Monit., 2007, 29, 612-618.

45 Y. Shen, R. Shrestha, A. Ibricevic, S. P. Gunsten, M. J. Welch, K. L. Wooley, S. L. Brody, J. S. Taylor and Y. Liu, Interface Focus, 2013, 3, 20120059.

46 C. Y. Shiue and S. Eck, in Handbook of Radiopharmaceuticals, ed. M. J. Welch and C. S. Redvanly, Wiley, New-York, USA, 2003, pp. 467-479.
47 X. Tian, M. R. Aruva, H. R. Wolfe, W. Qin, E. R. Sauter, M. L. Thakur, S. A. Waldman and E. Wickstrom, Nucleosides, Nucleotides Nucleic Acids, 2005, 24, 1085-1091. 48 G. Gasser, K. Jäger, M. Zenker, R. Bergmann, J. Steinbach, H. Stephan and N. Metzler-Nolte, J. Inorg. Biochem., 2010, 104, 1133-1140.

49 F. Chang, T. Qu, M. Rusckowski and D. J. Hnatowich, Appl. Radiat. Isot., 1999, 50, 723-732.

50 I. Eke, M. Ingargiola, C. Förster, L. A. Kunz-Schughart, M. Baumann, R. Runge, R. Freudenberg, J. Kotzerke, J. M. Heldt, H. J. Pietzsch, J. Steinbach and N. Cordes, Int. J. Radiat. Biol., 2014, 90, 678-686.

51 M. Ingargiola, R. Runge, J. M. Heldt, R. Freudenberg, J. Steinbach, N. Cordes, M. Baumann, J. Kotzerke, G. Brockhoff and L. A. Kunz-Schughart, Int. J. Cancer, 2014, 135, 968-980.

52 L. Koi, R. Bergmann, K. Brüchner, J. Pietzsch, H. J. Pietzsch, M. Krause, J. Steinbach, D. Zips and M. Baumann, Radiother. Oncol., 2014, 110, 362-369.

53 J. Saker, M. Kriegs, M. Zenker, J. M. Heldt, I. Eke, H. J. Pietzsch, R. Grenman, N. Cordes, C. Petersen, M. Baumann, J. Steinbach, E. Dikomey and U. KastenPisula, J. Nucl. Med., 2013, 54, 416-423.

54 M. Saki, M. Toulany, W. Sihver, M. Zenker, J. M. Heldt, B. Mosch, H. J. Pietzsch, M. Baumann, J. Steinbach and H. P. Rodemann, Strahlenther. Onkol., 2012, 188, 823-832.

55 J. Harding and B. Burtness, Drugs Today, 2005, 41, 107-127. 56 W. Sihver, J. Pietzsch, M. Krause, M. Baumann, J. Steinbach and H. J. Pietzsch, Pharmaceuticals (Basel), 2014, 7, 311338.

57 S. R. Hubbard and W. T. Miller, Curr. Opin. Cell Biol., 2007, 19, 117-123.

58 J. Schlessinger, Cell, 2000, 103, 211-225.

59 A. Gschwind, O. M. Fischer and A. Ullrich, Nat. Rev. Cancer, 2004, 4, 361-370.

60 T. Holbro, G. Civenni and N. E. Hynes, Exp. Cell Res., 2003, 284, 99-110.

61 N. E. Hynes and G. MacDonald, Curr. Opin. Cell Biol., 2009, 21, 177-184.

62 G. Lurje and H. J. Lenz, Oncology, 2009, 77, 400-410.

63 N. Tebbutt, M. W. Pedersen and T. G. Johns, Nat. Rev. Cancer, 2013, 13, 663-673.

64 C. Yewale, D. Baradia, I. Vhora, S. Patil and A. Misra, Biomaterials, 2013, 34, 8690-8707.

65 G. Gasser, in Peptide Nucleic Acids: Methods and Protocols, ed. P. E. Nielsen and D. H. Appella, Humana Press, 2014, vol. 1050, pp. 55-72.

66 G. Gasser, N. Hüsken, S. D. Köster and N. Metzler-Nolte, Chem. Commun., 2008, 3675-3677.

67 T. Bruckdorfer, in European Biopharmaceutical Review, Spring, 2008, pp. 96, 98, 100, 102, 104.

68 K. P. García, K. Zarschler, L. Barbaro, J. A. Barreto, W. O'Malley, L. Spiccia, H. Stephan and B. Graham, Small, 2014, 10, 2516-2529.

69 M. Hamidi, P. Rafiei and A. Azadi, Expert Opin. Drug Discovery, 2008, 3, 1293-1307. 
70 S. Jevsevar and R. Kontermann, Half-life extension through PEGylation Therapeutic Proteins, Strategies to Modulate Their Plasma Half-life, 2012.

71 K. Knop, R. Hoogenboom, D. Fischer and U. S. Schubert, Angew. Chem., Int. Ed., 2010, 49, 6288-6308.

72 F. Veronese and G. Pasut, Drug Discovery Today, 2005, 10, 1451-1458.

73 J. M. Harris and R. B. Chess, Nat. Rev. Drug Discovery, 2003, 2, 214-221.

74 P. Anstaett, Y. Zheng, T. Thai, A. M. Funston, U. Bach and G. Gasser, Angew. Chem., Int. Ed., 2013, 52, 4217-4220.

75 R. Bahal, N. A. McNeer, D. H. Ly, W. M. Saltzman and P. M. Glazer, Artificial DNA: PNA \& XNA, 2013, 4, 49-57.

76 G. M. Bonora, S. Drioli, M. Ballico, A. Faccini, R. Corradini, S. Cogoi and L. Xodo, Nucleosides, Nucleotides Nucleic Acids, 2007, 26, 661-664.

77 A. Cattani-Scholz, D. Pedone, F. Blobner, G. Abstreiter, J. Schwartz, M. Tornow and L. Andruzzi, Biomacromolecules, 2009, 10, 489-496.

78 M. Dettin, D. Silvestri, R. Danesin, E. Cretaio, G. Picariello, E. Casarin, A. Sonato, F. Romanato and M. Morpurgo, Molecules, 2012, 17, 11026-11045.

79 J. M. Goldman, L. A. Zhang, A. Manna, B. A. Armitage, D. H. Ly and J. W. Schneider, Biomacromolecules, 2013, 14, 2253-2261.

80 L. M. Kundu, H. Tsukada, Y. Matsuoka, N. Kanayama, T. Takarada and M. Maeda, Anal. Chem., 2012, 84, 52045209.

81 B. Sahu, I. Sacui, S. Rapireddy, K. J. Zanotti, R. Bahal, B. A. Armitage and D. H. Ly, J. Org. Chem., 2011, 76, 56145627.

82 Z. Zhang, Y. Liu, C. Jarreau, M. J. Welch and J.-S. A. Taylor, Biomater. Sci., 2013, 1, 1055-1064.

83 C. Foerster, M. Schubert, R. Bergmann, S. Vonhoff, S. Klussmann, M. Walther, J. Pietzsch, H.-J. Pietzsch and J. Steinbach, in Technetium and Other Radiometals in Chemistry and Medicine, ed. U. Mazzi, W. C. Eckelman and W. A. Volkert, SGEditoriali, Padova, Italy, 2010, pp. 357-362.

84 Y. Humblet, Expert Opin. Pharmacother., 2004, 5, 16211633.
85 B. Vincenzi, A. Zoccoli, F. Pantano, O. Venditti and S. Galluzzo, Curr. Cancer Drug Targets, 2010, 10, 80-95.

86 T. M. Brand, M. Iida and D. L. Wheeler, Cancer Biol. Ther., 2011, 11, 777-792.

87 K. Zarschler, K. Prapainop, E. Mahon, L. Rocks, M. Bramini, P. M. Kelly, H. Stephan and K. A. Dawson, Nanoscale, 2014, 6, 6046-6056.

88 C. S. Cutler, H. M. Hennkens, N. Sisay, S. Huclier-Markai and S. S. Jurisson, Chem. Rev., 2013, 113, 858-883.

89 E. W. Price and C. Orvig, Chem. Soc. Rev., 2014, 43, 260-290.

90 C. F. Ramogida and C. Orvig, Chem. Commun., 2013, 49, 4720-4739.

91 T. J. Wadas, E. H. Wong, G. R. Weisman and C. J. Anderson, Chem. Rev., 2010, 110, 2858-2902.

92 G. Liu, S. Zhang, J. He, N. Liu, S. Gupta, M. Rusckowski and D. J. Hnatowich, Q. J. Nucl. Med., 2002, 46, 233-243.

93 J. He, G. Liu, S. Dou, S. Gupta, M. Rusckowski and D. Hnatowich, Bioconjugate Chem., 2007, 18, 983-988.

94 W. H. Kuijpers, E. S. Bos, F. M. Kaspersen, G. H. Veeneman and C. A. van Boeckel, Bioconjugate Chem., 1993, 4, 94-102.

95 R. Alberto, R. Schibli, A. Egli, A. P. Schubiger, U. Abram and T. A. Kaden, J. Am. Chem. Soc., 1998, 120, 7987-7988.

96 J. Y. Song, S. W. Lee, J. P. Hong, S. E. Chang, H. Choe and J. Choi, Cancer Lett., 2009, 283, 135-142.

97 H. Björkelund, L. Gedda and K. Andersson, PLoS One, 2011, 6, e16536.

98 Z. Novy, P. Barta, J. Mandikova, M. Laznicek and F. Trejtnar, Nucl. Med. Biol., 2012, 39, 893-896.

99 M. Azemar, M. Schmidt, F. Arlt, P. Kennel, B. Brandt, A. Papadimitriou, B. Groner and W. Wels, Int. J. Cancer, 2000, 86, 269-275.

100 M. M. Moasser, A. Basso, S. D. Averbuch and N. Rosen, Cancer Res., 2001, 61, 7184-7188.

101 I. King and A. C. Sartorelli, Cancer Res., 1989, 49, 56775681.

102 D. T. Reardan, C. F. Meares, D. A. Goodwin, M. McTigue, G. S. David, M. R. Stone, J. P. Leung, R. M. Bartholomew and J. M. Frincke, Nature, 1985, 316, 265-268.

103 K. Zarschler, S. Witecy, F. Kapplusch, C. Foerster and H. Stephan, Microb. Cell Fact., 2013, 12, 97. 